\title{
Staphylococcus epidermidis is largely dependent on iron availability to form biofilms
}

\author{
Fernando Oliveira, Ângela França, Nuno Cerca* \\ Centre of Biological Engineering, LIBRO - Laboratory of Research in Biofilms Rosário Oliveira, University of Minho, Campus de Gualtar, 4710-057, Braga, Portugal
}

\section{A R T I C L E I N F O}

\section{Keywords:}

Staphylococcus epidermidis

Biofilm formation

Iron

\begin{abstract}
A B S T R A C T
Staphylococcus epidermidis has long been known as a major bacterial coloniser of the human skin, yet it is also a prominent nosocomial pathogen. Its remarkable ability to assemble structured biofilms has been its major known pathogenic feature to date. Notwithstanding important discoveries that have been accomplished, several questions about $S$. epidermidis biofilm formation still remain to be elucidated. This study aimed to assess whether iron availability modulates $S$. epidermidis biofilm formation and, if so, to explore how such modulation occurs. Biofilms of three $S$. epidermidis strains were grown under iron-enriched/-deficient conditions and several physiologic and transcriptomic changes were assessed. Our data revealed that while physiologic iron levels do not compromise biofilm formation, iron excess or deficiency is detrimental for this process. Conversely, biofilm cells were not affected in the same way when grown planktonically. By studying biofilm cells in detail we found that their viability and cultivability were seriously compromised by iron deficiency. Also, a temporal analysis of biofilm formation revealed that iron excess/deficiency: i) impaired biomass accumulation from $6 \mathrm{~h}$ onwards, and ii) induced changes in the biofilm structure, indicating that iron availability plays a pivotal role from an early biofilm development stage. The expression of several putative iron-related genes, namely encoding siderophore biosynthesis/transport-related proteins, was found to be modulated by iron availability, providing a biological validation of their function on $S$. epidermidis iron metabolism. This study therefore provides evidence that iron plays a pivotal role on $S$. epidermidis biofilm formation.
\end{abstract}

\section{Introduction}

As a common bacterial coloniser of the human skin and mucous membranes, Staphylococcus epidermidis often develops a benign relationship with its host. However, such barriers can somehow get damaged (e.g. insertion of indwelling medical devices), allowing this bacterium, formerly deemed as a harmless microorganism, to penetrate through the epithelial protective layer and become a threat, especially in immunocompromised patients (Cheung and Otto, 2010). For this reason, $S$. epidermidis has emerged as one of the most important nosocomial pathogens (Otto, 2009). To protect themselves from agressions found both at their natural or non-natural habitat, bacterial cells largely rely on their striking ability to assemble themselves in multi-layered structures called biofilms (Mack et al., 2007). Commonly, biofilms are highly structured communities of microorganisms attached to a surface and embedded in a self-produced matrix of extracellular polymeric molecules (Rohde et al., 2007). It is well established that bacterial cells within a biofilm are more tolerant to antimicrobial therapy (Cerca et al., 2005), as well as to the mechanisms of the innate host defence
(Cerca et al., 2006). For such reasons, biofilm-associated infections have been regarded as a major problem in modern medicine, affecting millions of people over the world (Donlan, 2001). To assemble a biofilm structure, S. epidermidis takes two major steps: (i) adhesion to a surface, whether it be artificial or natural, and (ii) accumulation of bacterial cells and formation of multi-layered structures. Afterwards, detachment and/or dispersal of biofilm cells eventually occurs, originating a new biofilm at a different location (Rohde et al., 2006).

Notwithstanding all the important knowledge that have been accumulated during the last decades, there are still mechanisms involved in S. epidermidis biofilm formation that are yet to be understood. Recently, it was demonstrated that $S$. epidermidis biofilm cells exhibit an increased transcription of genes putatively involved in iron uptake and metabolism after contact with human blood (França et al., 2014); however, experimental studies about the role of these genes in this species are absent. The importance of iron for virtually all bacteria has long been known, so that they can replicate and possibly establish an infection (Skaar, 2010). While most of studies have been performed on planktonic cells, it is pivotal to understand the role of iron on the

\footnotetext{
* Corresponding author at: Centre of Biological Engineering, University of Minho, Campus de Gualtar, 4710 - 057, Braga, Portugal.

E-mail address: nunocerca@ceb.uminho.pt (N. Cerca).
} 
biofilm development process, since iron requirements for planktonic and biofilm growth are thought to be different (Weinberg, 2004). Iron has previously been shown to modulate biofilm formation in different bacterial species, including Staphylococcus aureus (Banin et al., 2005; Lin et al., 2012). However, the role of iron on S. epidermidis biofilm formation is currently unknown, hence this study aimed to shed light into this process.

\section{Materials and methods}

\subsection{Microorganisms, growth conditions and chemicals}

S. epidermidis RP62A (ATCC 35984) is a culture collection strain well-known for its remarkable biofilm-producing ability, and was used as a control strain. S. epidermidis PT11006 and PT12003 are clinical isolates obtained after patient informed consent under approval from the Ethics Committee Board of Hospital Geral de Santo António, Porto, Portugal (015/09: 014-DEFI/014-CES). All strains tested have been confirmed to be ica-positive (unpublished data). For each experiment, isolated colonies were picked from Tryptic Soy Agar (TSA, Liofilchem, Teramo, Italy) plates, inoculated into Tryptic Soy Broth (TSB) (Liofilchem), and incubated overnight $(\sim 16 \mathrm{~h})$ at $37^{\circ} \mathrm{C}$ with shaking at 120 rpm (ES-20 Shaker-Incubator, BioSan, Riga, Latvia). Iron (III) chloride $\left(\mathrm{FeCl}_{3}\right)$ was purchased from Sigma-Aldrich (St. Louis, MO, USA). 2,2'-bipyridine (Bip) was purchased from VWR (Carnaxide, Portugal). Bip was dissolved in absolute ethanol $(50 \mathrm{mg} / \mathrm{mL}$ stock) and stored at $-20{ }^{\circ} \mathrm{C}$ until further use.

\subsection{Biofilm formation assays}

Biofilms were grown either in 96- (for biofilm biomass quantification) or in 24-well (for gene expression analysis) microplates made of polystyrene plastic (Thermo Fisher Scientific Inc.). For confocal microscopy analysis, biofilms were grown in Lab-Tek ${ }^{\circledR}$ Chamber Slide $^{\mathrm{TM}}$ System 8 Well Permanox Slides (Thermo Fisher Scientific Inc.). Briefly, overnight cultures were adjusted with TSB to an optical density at $640 \mathrm{~nm}\left(\mathrm{OD}_{640}\right)$ equivalent to $\sim 2 \times 10^{8} \mathrm{CFU} / \mathrm{mL}$ and diluted 1:100 in TSB supplemented with $0.4 \%(\mathrm{w} / \mathrm{v})$ glucose $\left(\mathrm{TSB}_{\mathrm{G}}\right.$, Thermo Fisher Scientific Inc.), iron-enriched $\mathrm{TSB}_{\mathrm{G}}\left(\mathrm{TSB}_{\mathrm{G}}\right.$ containing different $\mathrm{FeCl}_{3}$ concentrations) and iron-depleted $\mathrm{TSB}_{\mathrm{G}}\left(\mathrm{TSB}_{\mathrm{G}}\right.$ containing different Bip concentrations). $\mathrm{pH}$ measurements of the different culture media tested were performed with Model 15 ph meter (Denver Instrument, NY USA). Bip was added to the medium and allowed to stand for at least $30 \mathrm{~min}$ prior inoculation. Subsequently, the diluted bacterial suspension was placed into the plates and incubated at $37^{\circ} \mathrm{C}$ with shaking at $120 \mathrm{rpm}$ (ES-20 Shaker-Incubator) for the appropriate period (from 6 to $24 \mathrm{~h}$ ).

\subsection{Quantification of biofilm biomass}

After incubation, the bacterial cells in suspension were removed carefully, biofilms were washed twice with $200 \mu \mathrm{L}$ of $0.9 \% \mathrm{NaCl}$, and then stained by crystal violet technique, as previously described (Stepanovic et al., 2007). Briefly, biofilms were fixed with methanol (Thermo Fisher Scientific Inc.) for $20 \mathrm{~min}$ and stained with 1\% (v/v) crystal violet (Merck Millipore, Darmstadt, Germany) for $15 \mathrm{~min}$. Excess stain was rinsed off with tap water and the stain bound to the biofilm was resolubilized with $33 \%(\mathrm{v} / \mathrm{v})$ glacial acetic acid (Thermo Fisher Scientific Inc.). Absorbance was measured at $570 \mathrm{~nm}\left(\mathrm{~A}_{570}\right)$ using a microplate reader (Synergy HT, BioTek Instruments, VT, USA). Experiments were run at least in triplicate with technical triplicates for each condition tested.

\subsection{Planktonic cells growth curves}

Planktonic growth was assessed at $37{ }^{\circ} \mathrm{C}$ in TSB containing a range of concentrations of $\mathrm{FeCl}_{3}$ or Bip. Overnight-grown bacteria were diluted in a conical flask to an $\mathrm{OD}_{640} \sim 0.1$ and then incubated at $37^{\circ} \mathrm{C}$, $120 \mathrm{rpm}$ (ES-20 Shaker-Incubator). $\mathrm{OD}_{640}$ was measured hourly up to $10 \mathrm{~h}$ of incubation (when appropriate, concentrated samples were diluted in TSB for accurate measurement). Three independent experiments were performed for each condition tested. OD data were transformed into $\ln (\mathrm{OD})$ and plotted versus time (h) to identify the exponential phase (linear portion of the graph). Growth rates $\left(\mu, \mathrm{h}^{-1}\right)$ were given by the slope of that portion, which was determined through linear regression. Doubling times $\left(t_{\mathrm{d}}, \mathrm{min}\right)$ were calculated according to Eq. (1).

$t_{d}=\frac{\ln 2}{\mu} \times 60$

\subsection{Cell cultivability and viability assessment}

$24 \mathrm{~h}$-old biofilms were grown as mentioned above. Suspended and biofilm cells were collected, centrifuged at $5 \mathrm{k} \times \mathrm{g}$ for $10 \mathrm{~min}$, resuspended in $1 \mathrm{~mL}$ of $0.9 \% \mathrm{NaCl}$ and then sonicated for $10 \mathrm{~s}$ at $30 \%$ amplitude, using a $13 \mathrm{~mm}$ probe tip (Cole-Parmer 750-W Ultrasonic Homogenizer 230 VAC, IL, USA). By following this process, cell clusters were disrupted without compromising cell viability (Freitas et al., 2014). Cultivability of both suspended and biofilm cells was assessed by CFU counting. Biofilm cells were further studied for viability through flow cytometry using SYBR Green and propidium iodide (PI) staining as optimized before (Cerca et al., 2011), with minor modifications. In brief, $20 \mu \mathrm{L}$ of cell suspension were mixed with $180 \mu \mathrm{L}$ of phosphate buffered saline (PBS) containing 1:80000 of SYBR Green (Invitrogen, CA, USA) and $20 \mu \mathrm{g} / \mathrm{mL}$ of propidium iodide (Sigma, MO, USA), and the number of cells assessed using an $\mathrm{EC} 80^{\mathrm{Tm}}$ flow cytometer (Sony Biotech, CA, USA). A total of 65000 events were acquired with a sample flow rate of $10 \mu \mathrm{L} / \mathrm{min}$. Data analysis was performed using $\mathrm{EC}^{\mathrm{T}}{ }^{\mathrm{TM}}$ 1.3.6 analysis software (Sony Biotech). Two to three biological replicates were performed for this analysis.

\subsection{Confocal laser scanning microscopy analysis}

Biofilms were formed on the chamber slide system as described above, and then stained with i) DAPI nucleic acid stain (Sigma-Aldrich, MO, USA) for visualisation of cells, and ii) wheat germ agglutinin (WGA) conjugated with Texas Red (Thermo Fisher Scientiifc, Inc.) for staining of $N$-acetylglucosaminyl residues. All staining procedures were performed according to the manufacturer's instructions. Stained biofilms were visualized under an Olympus FluoView FV1000 confocal laser scanning microscope (CLSM; Olympus FluoView FV1000, Olympus, Lisboa, Portugal). Biofilms were observed using a $40 \times$ water-immersion objective $(40 \times / 1.15 \mathrm{~W})$, and images of different regions of each surface were acquired with $640 \times 640$ resolution. Two independent biological experiments were performed, and representative images were selected. Images were reconstructed from average intensity projection through confocal image Z-stacks series using ImageJ (Schindelin et al., 2012).

\subsection{Gene expression analysis}

\subsubsection{RNA extraction}

RNA extraction from $S$. epidermidis biofilm cells was based on a previously optimized protocol (França et al., 2012). This method combines mechanical (glass beads) lysis of bacterial cells along with silica membrane-based RNA isolation (ExtractMe RNA Bacteria \& Yeast Kit, Blirt S.A., Poland). Bacterial biofilms were thoroughly washed as described before, scraped from the plate, pooled in $0.9 \% \mathrm{NaCl}$, and immediately placed on ice. Biofilm cells were centrifuged at $16 \mathrm{k} \times g$ for $10 \mathrm{~min}$ at $4{ }^{\circ} \mathrm{C}$ and the supernatant was discarded. Then, the bacterial pellet was thoroughly suspended in $600 \mu \mathrm{L}$ of RYBL Buffer (provided by the kit). The resulting suspension was transferred into $2 \mathrm{~mL}$ safe lock 
tubes containing $0.5 \mathrm{~g}$ of acid-washed 150-212 mm silica beads (Sigma, USA). The tubes were then placed into a cell disruptor (FastPrep ${ }^{\circ}-24$, MP Biomedicals, CA, USA) and run for $35 \mathrm{~s}$ at $6.5 \mathrm{~ms}^{-1}$. The samples were immediately placed on ice for $5 \mathrm{~min}$ and the beat-beading step was repeated thrice. Afterwards, samples were centrifuged at $16 \mathrm{k} \times g$ for $1.5 \mathrm{~min}$ at $4{ }^{\circ} \mathrm{C}$, the supernatants transferred into $2 \mathrm{~mL}$ DNase/ RNase-free tubes and mixed with an equal volume of $70 \%$ ethanol. The samples (including any remaining precipitate) were transferred to the silica-membrane columns and centrifuged at $15 \mathrm{k} \times g$ for $1 \mathrm{~min}$ at room temperature (RT). The following steps were performed according to the manufacturer's instructions.

\subsubsection{DNase treatment}

To degrade genomic DNA, each RNA sample was digested with $2 \mu \mathrm{L}$ of DNase I plus $4 \mu \mathrm{L}$ of $10 \times$ DNase I Reaction Buffer, and incubated at $37^{\circ} \mathrm{C}$ for $30 \mathrm{~min}$. Then, to inactivate the DNase I activity, $4 \mu \mathrm{L}$ of $25 \mathrm{mM}$ EDTA ( $\mathrm{pH}$ 8.0) were added to the mixture and incubated at $65{ }^{\circ} \mathrm{C}$ for $10 \mathrm{~min}$. All reagents were purchased from Thermo Fisher Scientific Inc.

\subsubsection{RNA quality determination}

The concentration and purity of the total RNA was spectrophotometrically determined using a NanoDrop 1000 (Thermo Fisher Scientific Inc.). $A_{260} / A_{280}$ and $A_{260} / A_{230}$ ratios were used as indicators of protein and polysaccharide/phenol/chaotropic salts contamination, respectively. RNA integrity was assessed by visualisation of the 23S/ $16 \mathrm{~S}$ rRNA band pattern. RNA samples were analysed in $1 \%$ agarose gel. Non-denaturing electrophoresis was carried-out at $80 \mathrm{~V}$ for $60 \mathrm{~min}$. The gel was stained with Midori Green DNA staining (Nippon Genetics Europe GmbH, Germany) in TAE buffer (Tris-acetate-EDTA) and visualized using ChemiDoc ${ }^{\mathrm{TM}} \mathrm{XRS}+($ Bio-Rad, CA, USA). RNA was stored at $-80^{\circ} \mathrm{C}$ until further use.

\subsection{4. cDNA synthesis}

cDNA synthesis was performed using the RevertAid First Strand cDNA Synthesis Kit (Thermo Fisher Scientific, Inc.) following the manufacturer's instructions. The same amount of total RNA (300 ng) from each sample was reverse transcribed in a $10 \mu \mathrm{L}$ reaction volume using random hexamer primers as priming strategy. To determine the possibility of genomic DNA carry-over, control reactions were performed under the same conditions but lacking the reverse transcriptase enzyme (NRT control). All RNA samples extracted were absent of significant genomic DNA, as determined by an average quantification cycle $\left(\mathrm{C}_{\mathrm{q}}\right)$ difference of $18.16 \pm 3.89$.

\subsubsection{Gene expression quantification}

Biofilm cells gene expression was determined by quantitative realtime PCR (qPCR). qPCR analysis was performed using Xpert iFast SYBR Mastermix (GRiSP, Lda., Porto, Portugal) in a $10 \mu \mathrm{L}$ reaction volume. Each PCR reaction contained $2 \mu \mathrm{L}$ of 1:200 diluted cDNA or NRT control, $5 \mu \mathrm{L}$ of master mix, $1 \mu \mathrm{L}$ of primer mixture (in the final reaction, each primer was at $0.3 \mu \mathrm{M}$ ), and $2 \mu \mathrm{L}$ of nuclease-free water. qPCR runs were performed on a CFX 96 (BioRad) with the following cycle parameters: $95^{\circ} \mathrm{C}$ for $3 \mathrm{~min}$, and 40 cycles of $95{ }^{\circ} \mathrm{C}$ for $5 \mathrm{~s}$, and $60{ }^{\circ} \mathrm{C}$ for $25 \mathrm{~s}$. Melt analysis was performed at the end to ensure the absence of unspecific products and primer dimer. All genes were quantified in duplicate for biological triplicates. The expression of the genes tested was normalised to the expression of the reference gene 16S rRNA using the Pfaffl method (Pfaffl and Pfaffl, 2001), and considering TSB $_{\mathrm{G}}$ as the control condition. Data were $\log$ transformed $\left(\log _{2}\right)$ before statistical analysis was performed. Information about the primers used in this study is listed in Table 1. Primers were designed with the aid of Primer3 (Untergasser et al., 2012) using $S$. epidermidis RP62A genome sequence (NCBI accession no. NC_002976) as template. mFold was used for prediction of secondary structures (Zuker, 2003). No secondary structures were found for the operating temperatures used. Gene specificity of all primers was confirmed using Primer-BLAST (Ye et al., 2012). PCR amplification efficiency $(E)$ for each gene was determined from the slope of a standard curve (generated with a 10-fold dilution series of cDNA), according to Eq. (2).

$E=10\left[-\frac{1}{\text { slope }}\right]$

\subsection{In silico analysis}

Sequences of different putative iron-related proteins were retrieved from S. epidermidis RP62A (NCBI accession no. NC_002976) and queried against $S$. aureus strain Newman (NCBI accession no. NC_009641) to search for homologous proteins. Analysis was performed with BLASTp tool (Altschul et al., 1990) using the default parameters. Identification of putative Fur boxes in S. epidermidis RP62A genome were performed with FIMO tool (Grant et al., 2011), using the default parameters and the 19 bp Fur box consensus sequence GATAATGATAATCATTATC (De Lorenzo et al., 1987) as the input motif.

\subsection{Iron quantification}

Total iron concentration was assessed by a ferrozine-based method, adapted from Mladěnka et al. (Mladěnka et al., 2010). Briefly, $100 \mu \mathrm{L}$ of ammonium iron (II) sulfate standards (containing 0.1-10 nmol iron (II)) or culture medium samples were initially mixed with $50 \mu \mathrm{L}$ of $1.4 \mathrm{M}$ hydroxylamine aqueous solution to prevent iron (II) oxidation and/or to reduce any iron (III) present in the samples. After $30 \mathrm{~min}, 50 \mu \mathrm{L}$ of $5 \mathrm{mM}$ ferrozine solution (in $5 \mathrm{M}$ ammonium acetate buffer, $\mathrm{pH}$ 9.5) was added to the mixture. All reagents were purchased from VWR. Formation of the iron-ferrozine complex was then determined at $562 \mathrm{~nm}$. All experiments were performed in 96-well microplates. Absorbance was measured at $562 \mathrm{~nm}$ using a microplate reader (Synergy HT). Two independent experiments with technical duplicates were performed for each standard or sample.

\subsection{Statistical analysis}

Data transformation, linear regressions and statistical analysis were performed with GraphPad Prism version 7.0a (La Jolla, CA, USA). For comparisons among different groups, two-away ANOVA with multiple comparisons test was used. A $p<0.05$ was considered statistically significant.

\section{Results}

\subsection{Biofilm formation is highly modulated by iron availability}

Biofilm formation in $\mathrm{TSB}_{\mathrm{G}}$ alone (total iron content of $6.30 \pm 0.47 \mu \mathrm{M}$, as determined by the ferrozine-based method) or supplemented with iron concentrations up to $0.10 \mathrm{mM} \mathrm{FeCl}_{3}$, which covers the physiologic serum iron concentrations usually found in humans (0.01-0.04 mM) (Worwood, 2014), was similar (Fig. 1A). However, a supraphysiologic iron concentration in the order of $1.00 \mathrm{mM}$ did have a detrimental effect on biofilm accumulation. Biofilm formation ability was also evaluated under iron-limiting conditions, which have been attained by the use of the synthetic iron chelator 2,2'-bipyridine (Bip). Bip has been widely employed for iron depletion in different culture media (Hayrapetyan et al., 2016; Lin et al., 2012; Reid et al., 2009). All strains exhibited significant decrease in biofilm formation under this condition, especially when Bip concentrations reached very high levels (from 0.50 to $1.00 \mathrm{mM}$ ) (Fig. 1B). To discard the hypothesis that these observations were instead the result of the ethanol used to dissolve Bip, biofilm formation in $\mathrm{TSB}_{\mathrm{G}}, 2 \%(\mathrm{v} / \mathrm{v})$ ethanol (concentration present in the highest Bip concentration tested) was also assessed. Although ethanol has been reported to modulate biofilm formation in $S$. 
Table 1

List of primers used in qPCR experiments and respective product size and amplification efficiencies.

\begin{tabular}{|c|c|c|c|c|}
\hline Target gene & Forward sequence $\left(5^{\prime}-3^{\prime}\right)$ & Reverse sequence $\left(5^{\prime}-3^{\prime}\right)$ & Product size (bp) & Efficiency $(\%)^{\mathrm{a}}$ \\
\hline $16 S$ rRNA & GGGCTACACACGTGCTACAA & GTACAAGACCGGGAACGTA & 176 & 89.7 \\
\hline SERP1775 & CTGCTGCTAAACTTGCCCCT & TCTGGCTCGGTGATACAAGG & 88 & 97.5 \\
\hline SERP1776 & GGAAGCACCTGCATTCACAC & GGCGCTTTAGCAATTGCAGG & 93 & 85.6 \\
\hline SERP1778 & GTTTATCCCCTGCGACACAT & GGCGAATGTTCGTGTCAAT & 119 & 87.4 \\
\hline SERP1779 & GCACTTTTTCGCGCTACTTT & TCGAACGATTAACGCAATGA & 129 & 96.8 \\
\hline SERP0306 & GTGGTGGACAAAGACAACGC & GCAACCTTCTTCTTCGTTGAGC & 152 & 90.2 \\
\hline SERP0400 & AGGGGTGAGTCAGCTCTCTT & GCCCACTCCATAGTACCAGC & 198 & 92.1 \\
\hline SERP0401 & ACTGGTCGTTATGGCAATTTGT & ACGGACGTTCCTATCGATGC & 141 & 100.2 \\
\hline SERP0402 & TCAGACGACATCATTGCGCT & ACGTTGTCCCCTTATCTCCTC & 132 & 96.4 \\
\hline SERP0403 & CAACGTTTGGACCAGGAGGA & TTTGACCATGCGGGCTTTTG & 99 & 90.0 \\
\hline SERP0949 & ACATCATCGTGGTGAAACGA & GCATTTCCTTGACCTTTTGC & 150 & 88.5 \\
\hline SERP1951 & CCTCTTGAGCACGACTAGCA & TGCTTTCAGGTGGACAACAA & 117 & 94.0 \\
\hline SERP1953 & TCACAAGTGGAGAAGCATCACT & CAGTCCCACTTAGAAATGCACG & 195 & 92.1 \\
\hline
\end{tabular}

${ }^{\text {a }}$ Amplification efficiency was calculated as described in Materials and Methods.

epidermidis (Knobloch et al., 2002), our results showed that ethanol at such concentration did not affect biofilm formation for the strains tested here (Fig. S1). Moreover, supplementation with $\mathrm{FeCl}_{3}$ or Bip did not change the $\mathrm{pH}$ of the culture medium (Table S1), thus $\mathrm{pH}$ effects were also ruled out.

Another issue of using an iron chelator is that it might chelate other important trace metals (e.g. calcium or magnesium) at some degree. To confirm that the effect observed was actually due to the sequestration of iron, biofilm formation was screened in iron-depleted medium $\left(\mathrm{TSB}_{\mathrm{G}}\right.$, $1.00 \mathrm{mM}$ Bip) complemented with a range of increasing $\mathrm{FeCl}_{3}$ concentrations (up to $1.00 \mathrm{mM}$ ). The impaired biofilm formation was fully reversed by co-addition of iron in a dose-dependent manner up to $0.2 \mathrm{mM} \mathrm{FeCl}_{3}$ (Fig. 2). As previously observed, higher concentrations had a detrimental effect. Similar experiments were performed with co-
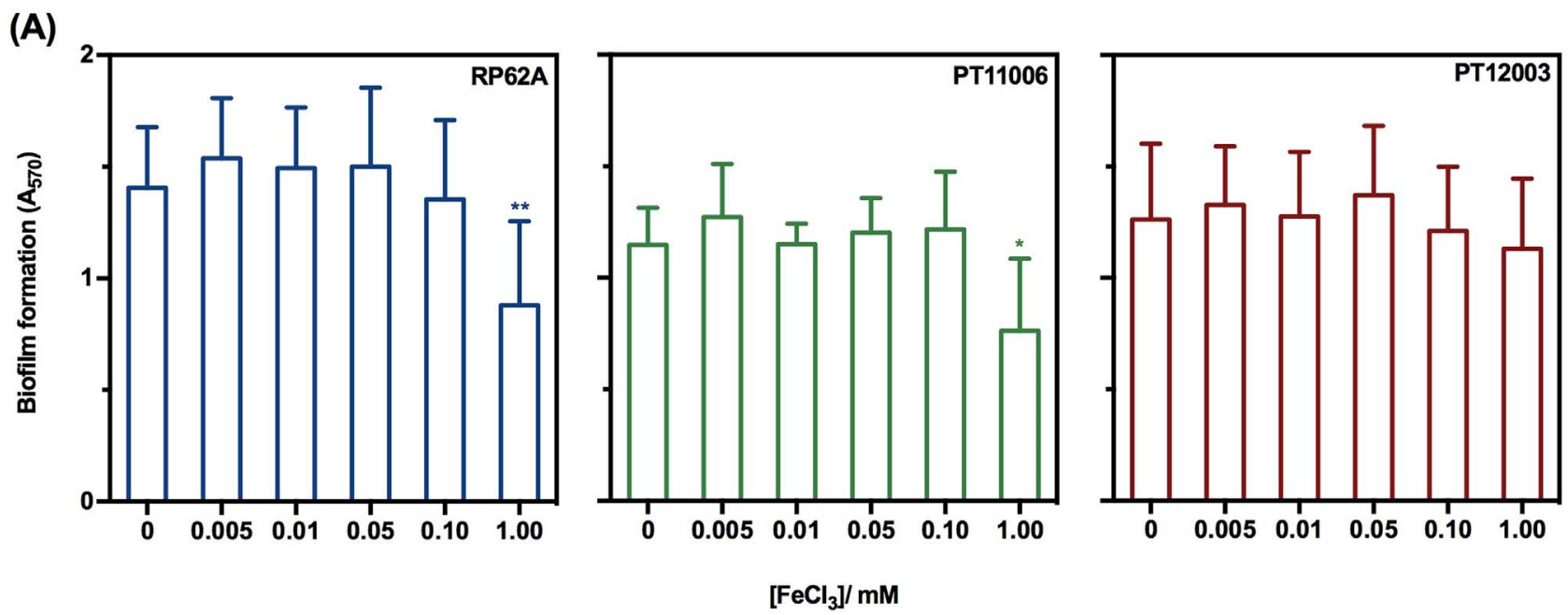

(B)
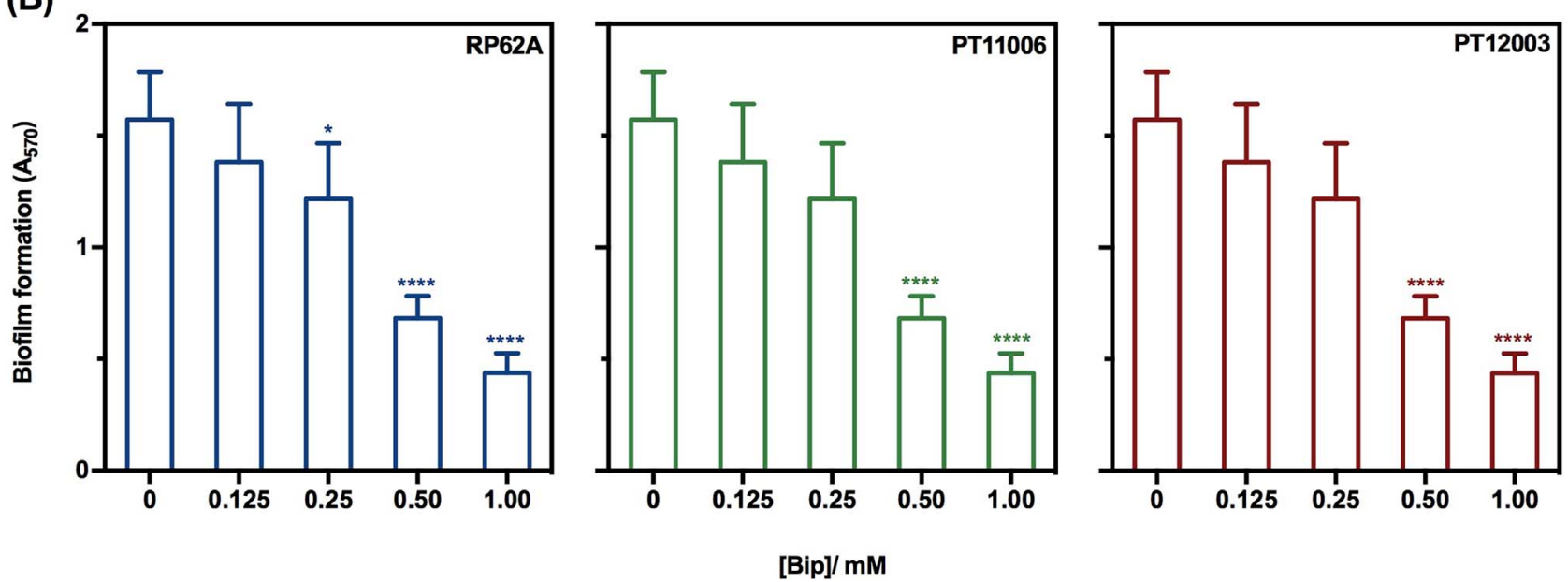

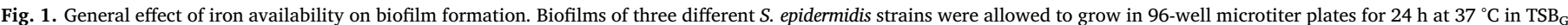

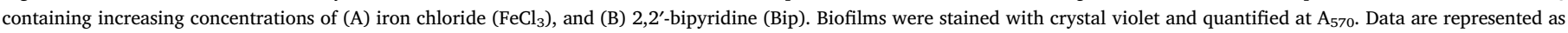
mean \pm standard deviation of at least three independent assays. Significant differences are depicted with: ${ }^{*} p<0.05 ; * * p<0.01 ; * * * p<0.0001$. 

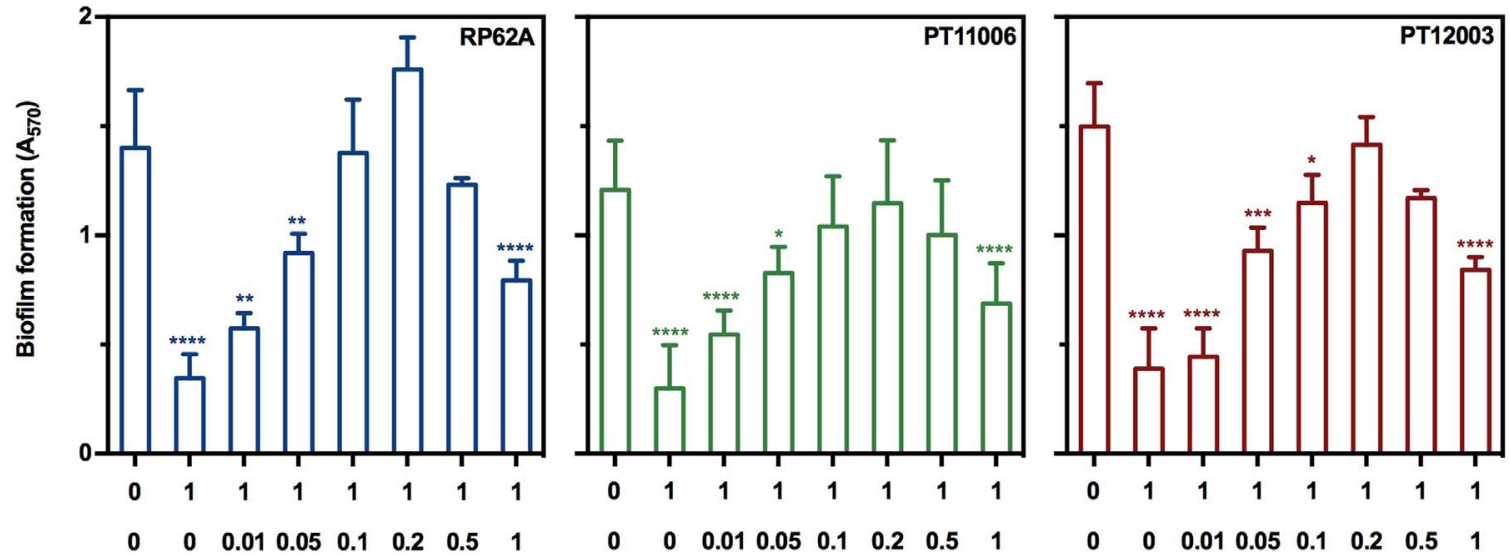

Bip (mM)

$\mathrm{FeCl}_{3}(\mathrm{mM})$

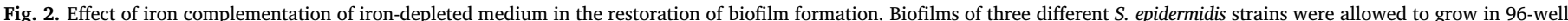

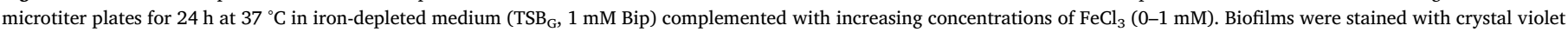

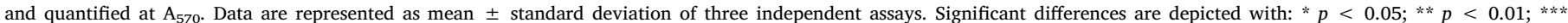
$p<0.001 ; * * * *<<0.0001$.

addition of calcium and magnesium ions (in the form of $\mathrm{CaCl}_{2}$ and $\mathrm{MgCl}_{2}$, respectively), but the effect was not reversed (Fig. S2). These results therefore strongly suggest that the effects observed are attributable to iron sequestration.

\subsection{S. epidermidis withstands higher variations in iron availability when grown planktonically}

Given the pivotal role of iron on a myriad of basic physiologic processes, it was hypothesized that effects observed on biofilm formation could be attributable to an impaired cell growth rate. To assess this, planktonic cells were grown under the exactly same conditions (Fig. 3; Table 2). Not surprisingly, iron concentrations up to $0.10 \mathrm{mM}$ were not detrimental for planktonic growth. Furthermore, and in opposition to biofilms, supplementation with $1.00 \mathrm{mM} \mathrm{FeCl}_{3}$ had no significant $(p>0.05)$ effect on the planktonic growth rate. On the other hand, when iron in the culture medium was depleted, cell growth was partly affected in a dose-dependent manner, with a significant increase
Table 2

Doubling times (td, in min) of $S$. epidermidis grown in TSB containing increasing concentrations of $\mathrm{FeCl}_{3}$ and Bip. Significant differences are depicted with: $* * p<0.01 ; * * * *$ $p<0.0001$

\begin{tabular}{llll}
\hline Condition & RP62A & PT11006 & PT12003 \\
\hline TSB & $54.0 \pm 7.4$ & $50.5 \pm 3.2$ & $59.1 \pm 4.6$ \\
TSB + 0.01 mM FeCl & $52.3 \pm 11.9$ & $52.2 \pm 11.6$ & $69.5 \pm 10.3$ \\
TSB + 0.10 mM FeCl & $49.7 \pm 14.4$ & $50.4 \pm 8.9$ & $53.2 \pm 2.5$ \\
TSB + 1.00 mM FeCl & $49.6 \pm 11.2$ & $62.5 \pm 17.7$ & $54.7 \pm 5.1$ \\
TSB + 0.25 mM Bip & $58.7 \pm 4.6$ & $50.9 \pm 2.8$ & $58.9 \pm 7.2$ \\
TSB + 0.50 mM Bip & $59.0 \pm 6.5$ & $54.1 \pm 1.4$ & $67.3 \pm 5.3$ \\
TSB + 1.00 mM Bip & $68.1 \pm 6.2^{* *}$ & $64.7 \pm 5.4^{* *}$ & $80.4 \pm 2.9 *^{* * * *}$ \\
\hline
\end{tabular}

$(p<0.05)$ in the doubling time when Bip reached a concentration of $1 \mathrm{mM}$ (Table 2). Additionally, a lower cell density after $10 \mathrm{~h}$ of incubation was also noticed.
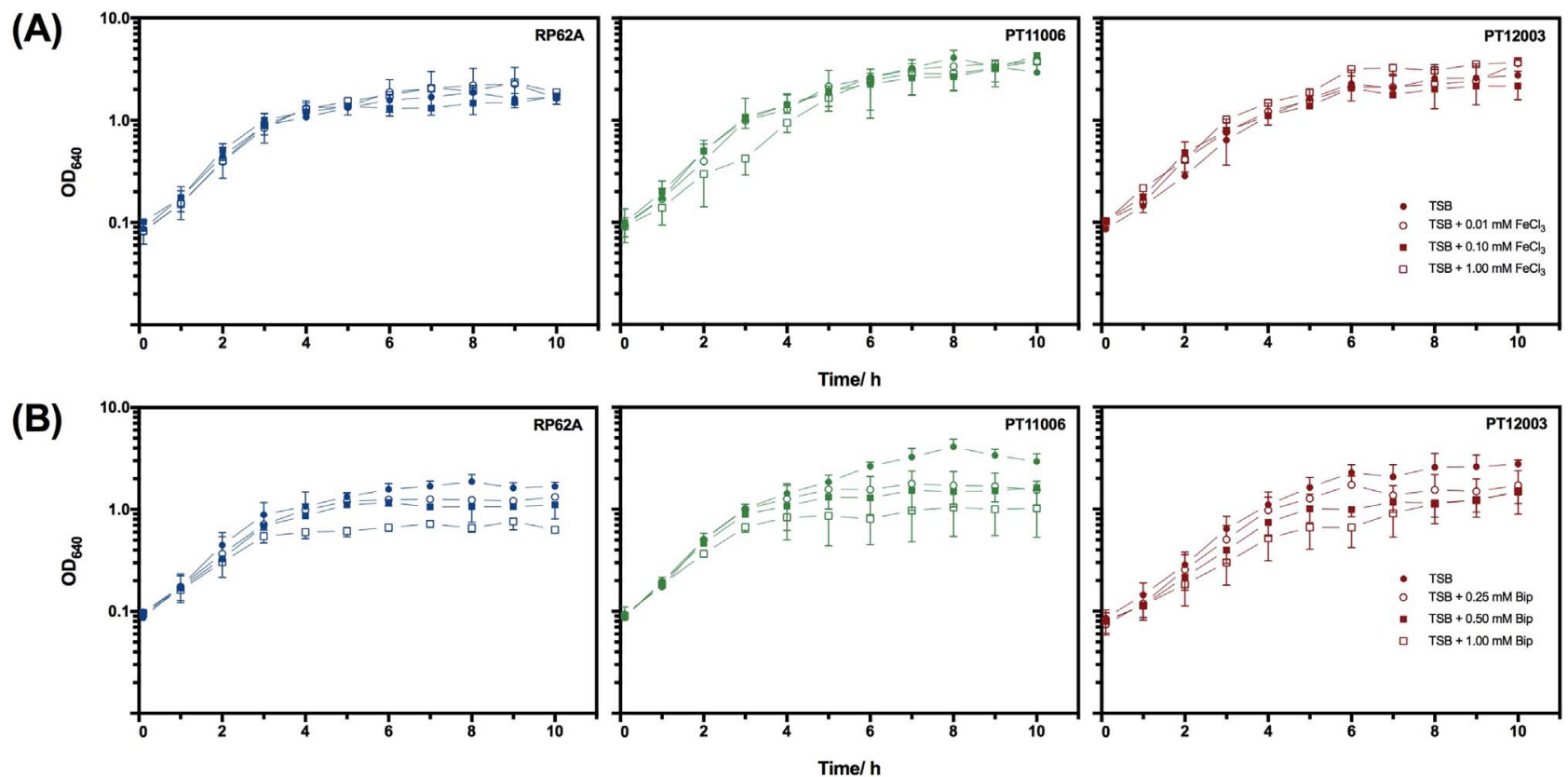

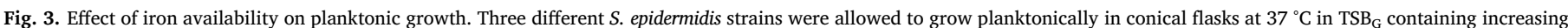

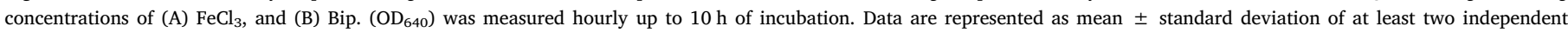
experiments. 
Table 3

Cultivability of biofilm (B) and suspended (S) cells grown under different iron availability conditions

\begin{tabular}{|c|c|c|c|c|c|c|c|c|c|}
\hline \multirow[t]{3}{*}{ Condition } & \multicolumn{3}{|l|}{ RP62A } & \multicolumn{3}{|l|}{ PT11006 } & \multicolumn{3}{|l|}{ PT12003 } \\
\hline & \multicolumn{2}{|l|}{$\log _{10} \mathrm{CFU} / \mathrm{mL}$} & \multirow[t]{2}{*}{$\mathrm{B}: \mathrm{S}^{\mathrm{a}}$} & \multicolumn{2}{|l|}{$\log _{10} \mathrm{CFU} / \mathrm{mL}$} & \multirow[t]{2}{*}{$\mathrm{B}: \mathrm{S}^{\mathrm{a}}$} & \multicolumn{2}{|l|}{$\log _{10} \mathrm{CFU} / \mathrm{mL}$} & \multirow[t]{2}{*}{$\mathrm{B}: \mathrm{S}^{\mathrm{a}}$} \\
\hline & Biofilm cells & Suspended cells & & Biofilm cells & Suspended cells & & Biofilm cells & Suspended cells & \\
\hline $\mathrm{TSB}_{\mathrm{G}}+1.00 \mathrm{mM}$ Bip & $7,29 \pm 0,42$ & $6,46 \pm 0,40$ & $87: 13$ & $7,26 \pm 0,42$ & $6,04 \pm 0,59$ & $94: 6$ & $6,29 \pm 0,40$ & $6,80 \pm 0,26$ & $24: 76$ \\
\hline $\mathrm{TSB}_{\mathrm{G}}+0.50 \mathrm{mM} \mathrm{Bip}$ & $7,84 \pm 0,41$ & $6,59 \pm 0,41$ & $95: 5$ & $7,47 \pm 0,49$ & $6,01 \pm 0,50$ & $97: 3$ & $8,30 \pm 0,17$ & $7,77 \pm 0,27$ & $77: 23$ \\
\hline $\mathrm{TSB}_{\mathrm{G}}$ & $8,43 \pm 0,14$ & $8,42 \pm 0,17$ & $50: 50$ & $8,39 \pm 0,12$ & $7,98 \pm 0,26$ & $72: 28$ & $8,63 \pm 0,17$ & $8,60 \pm 0,15$ & $50: 50$ \\
\hline $\mathrm{TSB}_{\mathrm{G}}+0.10 \mathrm{mM} \mathrm{FeCl}_{3}$ & $8,31 \pm 0,35$ & $8,17 \pm 0,45$ & $58: 42$ & $8,57 \pm 0,39$ & $8,12 \pm 0,30$ & $73: 27$ & $8,73 \pm 0,50$ & $8,59 \pm 0,33$ & $58: 42$ \\
\hline $\mathrm{TSB}_{\mathrm{G}}+1.00 \mathrm{mM} \mathrm{FeCl}_{3}$ & $8,42 \pm 0,31$ & $7,71 \pm 0,72$ & $83: 17$ & $8,65 \pm 0,47$ & $7,69 \pm 0,46$ & $90: 10$ & $8,90 \pm 0,47$ & $8,10 \pm 0,46$ & $86: 14$ \\
\hline
\end{tabular}

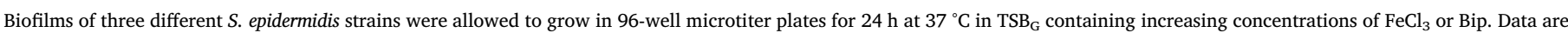
represented as mean \pm standard deviation of three independent experiments.

${ }^{\text {a }}$ Proportion of biofilm/suspended cells (B:S) is represented as percentages.

\subsection{Cultivability and viability of S. epidermidis biofilm cells are} compromised by iron deficiency but not by its excess

To further understand the physiologic changes induced by iron availability, the cultivability and viability of biofilm cells were assessed. Interestingly, cultivability was reduced in most cases when cells were cultured under iron-limiting conditions, despite not being compromised by excessive amounts of iron (Table 3). However, by analyzing the ratio biofilm/suspended cells, it was noted that biofilm cells represented the majority of the total cultivable cells when shifts in the iron concentration were introduced (except for strain PT12003 when cultured in $\mathrm{TSB}_{\mathrm{G}}, 1 \mathrm{mM}$ Bip). This observation also rules out the hypothesis that significant changes in iron availability induced cells to detach from the biofilm.

Similarly, flow cytometry experiments showed that total biofilm cell counts were significantly reduced under iron deficiency (up to 1-Log), but not under iron excess (Fig. 4A). Additionally, double staining with SYBR Green and propidium iodide (PI) has confirmed the results on cultivability, highlighting a greater proportion of dead and damaged cells under iron scarcity (Fig. 4B). An increment in the cell size was also noticed in both conditions (Table S2).

\subsection{Iron affects biofilm development from an early development stage}

A temporal analysis of biofilm formation (Fig. 5A) indicated that iron availability plays a major role right from an early development stage $(6 \mathrm{~h})$. Even though further biomass accumulation is noticeable across all conditions, this process is clearly hampered by shifts in iron availability, especially under low-iron conditions.

A similar set of experiments was carried out in a chamber slide
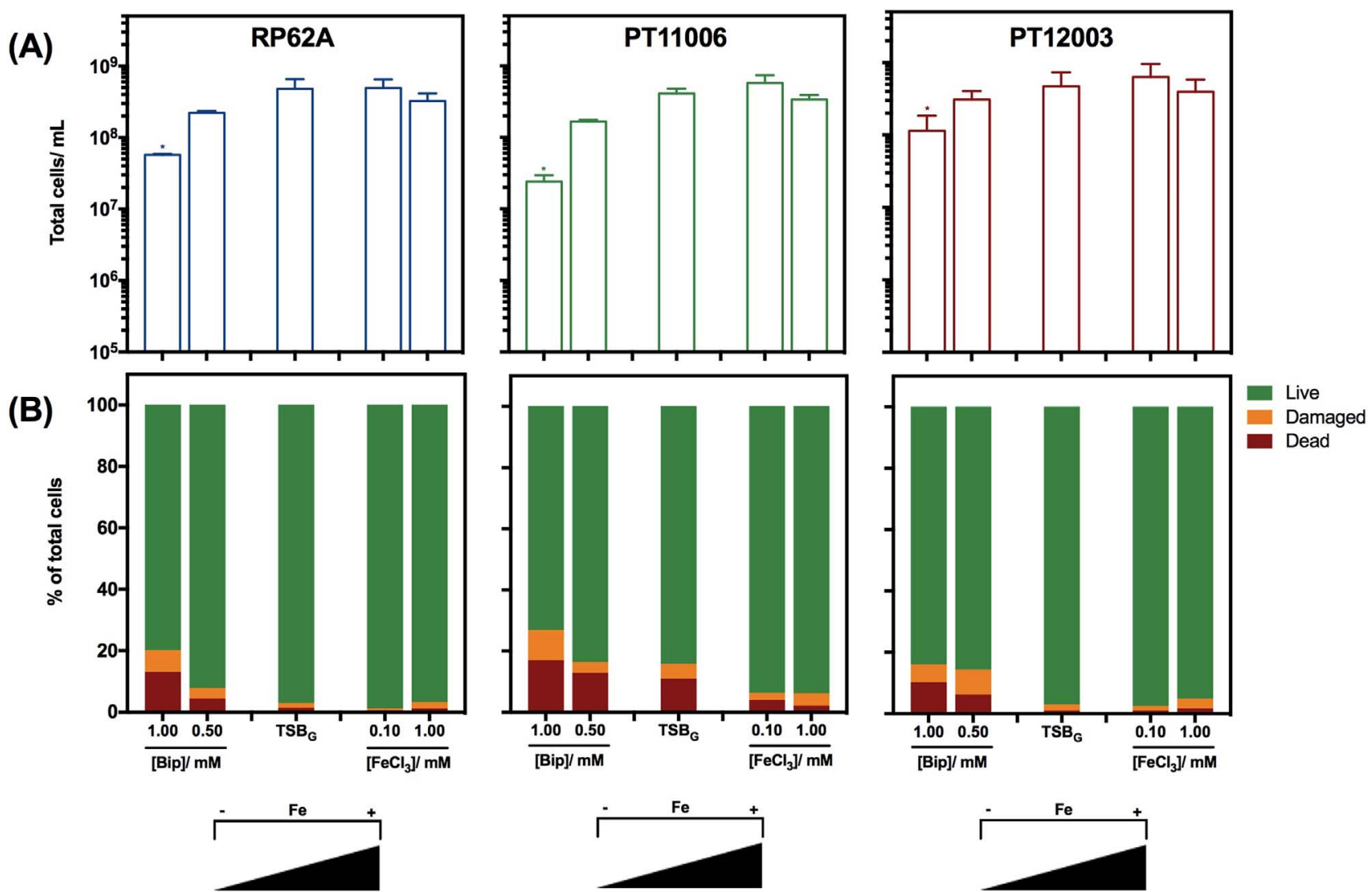

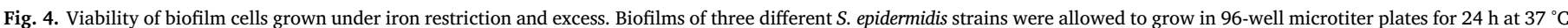

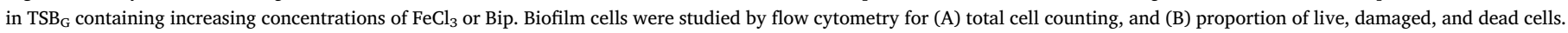
Data are represented as mean \pm standard deviation of two independent experiments. Significant differences are depicted with: ${ }^{*} p<0.05$. 
(A)
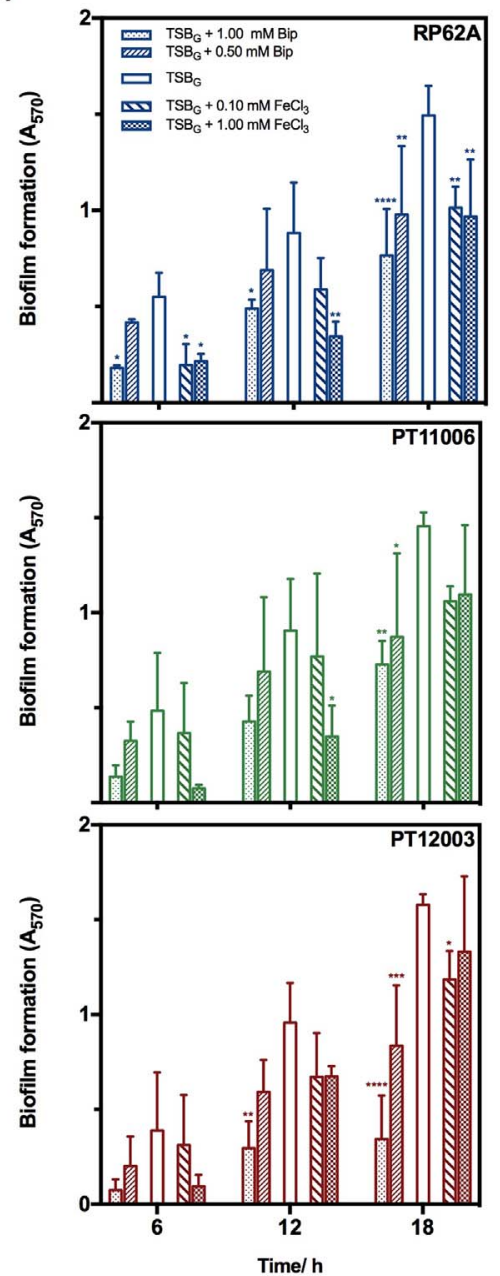

(B)

$6 \mathrm{H}$
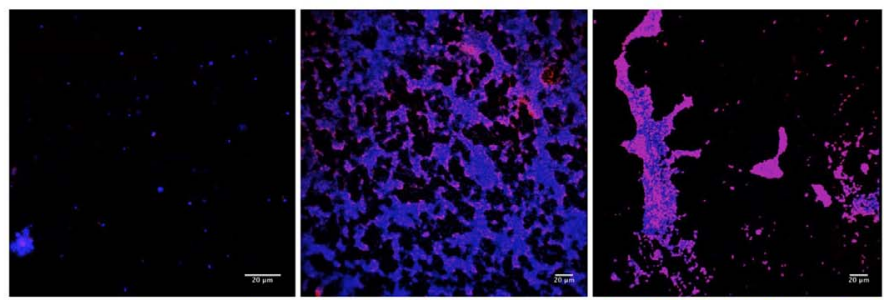

$12 \mathrm{H}$
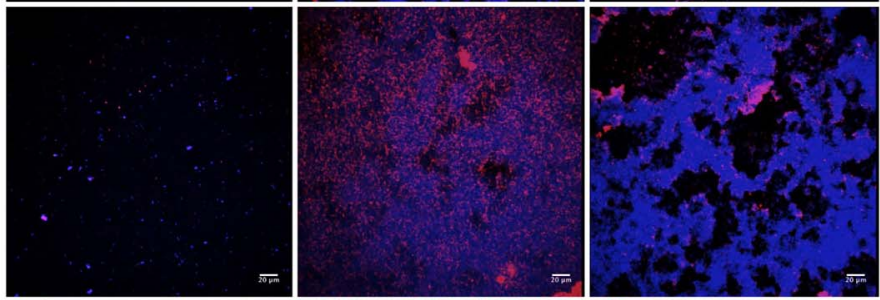

$18 \mathrm{H}$
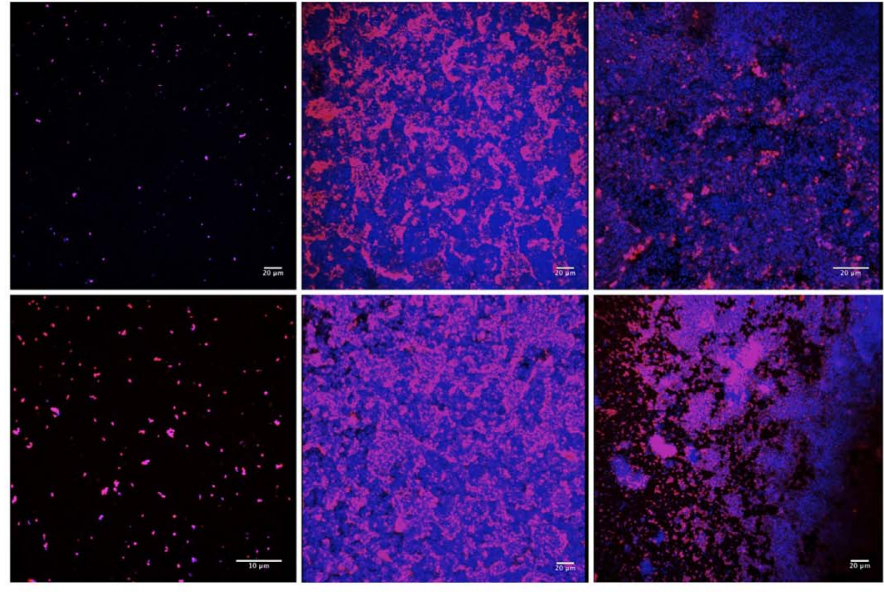

24H
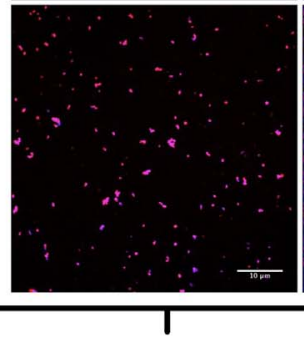

$\mathrm{Fe}^{-}$

$\mathrm{TSB}_{\mathrm{G}}$

$\mathrm{Fe}^{+}$

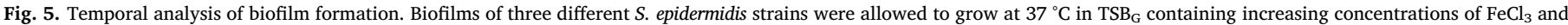

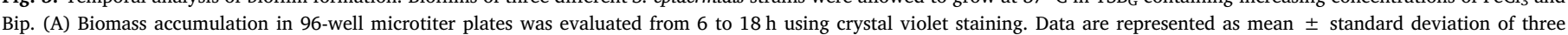

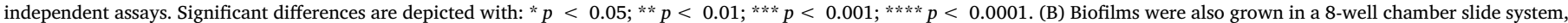

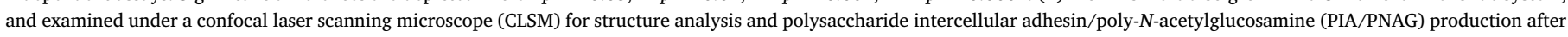
appropriate staining with DAPI (depicted in blue) and WGA-Texas Red (depicted in red). Representative images of each condition tested for strain PT12003 are shown.

system and biofilms were examined through confocal laser scanning microscopy (CLSM) for biofilm structure and polysaccharide intercellular adhesin/poly- $N$-acetylglucosamine (PIA/PNAG) production (Fig. 5B). PIA/PNAG has long been known as a major component of the staphyloccal biofilm matrix, and a key molecule for intercellular adhesion during biofilm accumulation (Jabbouri and Sadovskaya, 2010). When strains were grown in $\mathrm{TSB}_{\mathrm{G}}$, a classical staphylococcal biofilm structure was observed, with cells being evenly distributed across the surface and embedded by a prominent PIA/PNAG mesh. Conversely, iron excess $\left(\mathrm{Fe}^{+}\right)$seems to have a detrimental effect in biofilm accumulation during the first $12 \mathrm{~h}$, with cells being assembled mainly as clusters. This seems to be an initial adapation period after which cells are able to accumulate and achieve a wider distribution $(18 \mathrm{~h})$. However, an apparent decrease in biofilm formation from 18 to $24 \mathrm{~h}$ was observed. Although this observation may suggest a biofilm disruption event, we have evidence that this might simply be an artifact. In fact, $24 \mathrm{~h}$-old biofilms formed in the chamber slide system under iron excess proved to be very unstable, especially for strain RP62A, and slightly disrupted by the washing steps employed to remove loosly attached cells, an unpreventable phenomenon that usually occurs when using fed-batch systems (França et al., 2016).

This has led us to hypothesize that the extracellular biofilm matrix is somehow affected by excess iron. Staining with WGA showed that PIA/
PNAG production was not affected at this point, thus the effect observed is originated by another unknown mechanism. Lastly, biofilms formed under iron-depleted conditions $\left(\mathrm{Fe}^{-}\right)$exhibited a reduced number of cells throughout the period in analysis. Cells were found to be distributed across the surface mostly as microcolonies, being those structures surrounded with PIA/PNAG.

\subsection{Bioinformatics analysis of putative iron-related genes}

A recent study performed by França et al. highlighted a group of genes in $S$. epidermidis with putative function in iron uptake/homeostasis that were found to be differentially expressed after incubation of biofilm cells with human blood (França et al., 2014). To find out whether the proteins encoded by these genes share homology with proteins from $S$. aureus, which is far better characterized at the level of iron acquisition mechanisms, a bioinformatics analysis was carried out (Table 4). Products of the SERP1778-1781 locus (Fig. 6) share homology with the $s f a A B C D$-encoded enzymes, which have been demonstrated to be involved in the biosynthesis of a siderophore called staphyloferrin A (Beasley et al., 2009). Siderophores are low-molecular weight, high-affinity iron chelators capable of compete for iron with other host's iron-binding proteins, and are one of the most common iron acquisition systems among bacteria (Miethke and Marahiel, 2007). 
Table 4

BLAST closest matches of $S$. epidermidis RP62A putative iron-related proteins in $S$. aureus strain Newman

\begin{tabular}{|c|c|c|c|c|}
\hline S. epidermidis RP62A & S. aureus strain Newman & & & \\
\hline Protein & Protein & Function & Identity (\%) & Similarity (\%) \\
\hline SERP1775 & NWMN_2076 (HtsC) & Siderophore ABC transporter, permease & 75 & 90 \\
\hline SERP1776 & NWMN_2077 (HtsB) & Siderophore $\mathrm{ABC}$ transporter, permease & 72 & 89 \\
\hline SERP1777 & NWMN_2078 (HtsA) & Siderophore ABC transporter, lipoprotein & 72 & 84 \\
\hline SERP1778 & NWMN_2079 (SfaC) & Alanine racemase & 63 & 81 \\
\hline SERP1779 & NWMN_2080 (SfaB) & Siderophore synthetase & 64 & 78 \\
\hline SERP1780 & NWMN_2081 (SfaA) & MFS transporter & 75 & 90 \\
\hline SERP1781 & NWMN_2082 (SfaD) & IucA/IucC family siderophore biosynthesis protein & 60 & 75 \\
\hline SERP0306 & NWMN_0616 (FhuA) & Ferrichrome transport, ATP-binding protein & 84 & 92 \\
\hline SERP0400 & NWMN_0702 (SstA) & Siderophore ABC transporter, permease & 80 & 94 \\
\hline SERP0401 & NWMN_0703 (SstB) & Siderophore $\mathrm{ABC}$ transporter, permease & 72 & 89 \\
\hline SERP0402 & NWMN_0704 (SstC) & Siderophore ABC transporter, ATP-binding protein & 73 & 88 \\
\hline SERP0949 & NWMN_0705 (SstD) & Siderophore ABC transporter, lipoprotein & 70 & 85 \\
\hline SERP0403 & NWMN_0705 (SstD) & Siderophore ABC transporter, lipoprotein & 41 & 63 \\
\hline SERP1951 & NWMN_2261 (HrtA) & Heme $\mathrm{ABC}$ transporter, ATP-binding protein & 69 & 83 \\
\hline SERP1952 & NWMN_2262 (HrtB) & Heme $\mathrm{ABC}$ transporter, permease & 53 & 76 \\
\hline SERP1953 & NWMN_2263 (HssR) & Heme response regulator, DNA-binding protein & 71 & 87 \\
\hline SERP1954 & NWMN_2264 (HssS) & Sensor histidine kinase & 65 & 80 \\
\hline
\end{tabular}

Siderophore production in $S$. epidermidis has been reported before (Lindsay et al., 1994), although genetic information underlying siderophore biosynthesis in this species remains to be elucidated. Imediatelly upstream is the SERP1775-1777 locus whose products share homology with components of the $\mathrm{ABC}$ transporter HtsABC, that has been shown to be the transporter of iron-staphyloferrin A complexes (32). Interestingly, and similarly to $S$. aureus, this locus lacks a gene encoding the ATP-binding protein of a classical ABC-type transporter. In $S$. aureus, it has been demonstrated that the ATP-binding protein required for the internalization of both staphyloferrin A (Beasley et al., 2009) and B (Speziali et al., 2006) is FhuC. In S. epidermidis, and according to previous results (Beasley et al., 2009), SERP0306 seems to be the protein that plays that role, since it was found to be up-regulated when biofilm cells were cultured in human blood (França et al., 2014) and it shares homology with the $S$. aureus ATP-binding protein FhuA.

The products of the SERP0400-0402 locus are homologs of the $S$. aureus Sst system, described as a putative siderophore transporter (Morrissey et al., 2000), even though its substrate specificity is yet to be determined. In most bacterial species, and like the sfa-hts locus, genes encoding for siderophore transporters are usually found in the vicinity of the biosynthetic genes (Crosa and Walsh, 2002). However, products of the genes immediately up- or downstream this locus do not share homology with siderophore-related proteins from other species. Besides staphyloferrin A, another siderophore called staphyloferrin B has been identified and characterized in $S$. aureus, which is synthesized by the products of the $s b n$ loci (Hammer and Skaar, 2011), and internalized by the SirABC transporter (Beasley et al., 2011; Beasley and Heinrichs, 2010). However, Sbn homologs have not been found in S. epidermidis, and the only proteins that share homology with SirABC are SERP17751777.

SERP0949 and SERP0403 genes have been annotated as transferrinbinding proteins. However, bioinformatics analysis has shown that SERP0403, and SERP0949 at a lower degree, shares homology with $S$. aureus SstD, which is the substrate-binding protein of the previously discussed Sst transporter.

SERP1951 and SERP1953 are homologs of S. aureus HrtA and HssR, respectively. Together with HrtB (SERP1952), HrtA forms the efflux pump HrtAB that plays a significant function in intracellular heme homeostasis and control of heme-associated toxicity. HrtAB is in turn activated by the two-component regulatory system HssRS (SERP19531954) in response to heme exposure (Friedman et al., 2006; Torres et al., 2007).

Identification of putative Fur boxes up- or downstream these genes/ loci was also performed. Ferric uptake regulator (Fur) protein regulates

\section{S. epidermidis RP62A}

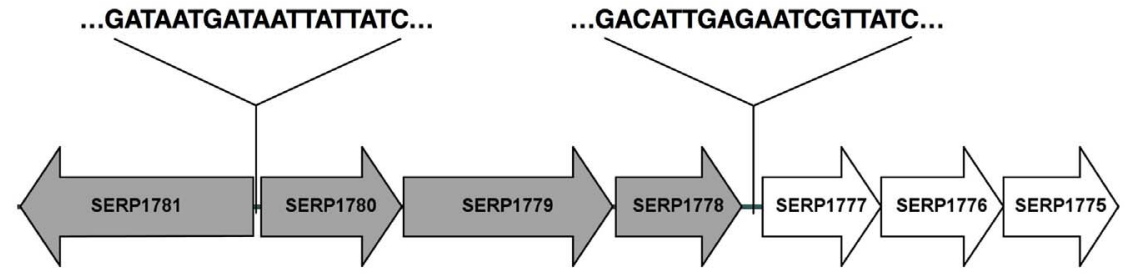

S. aureus strain Newman

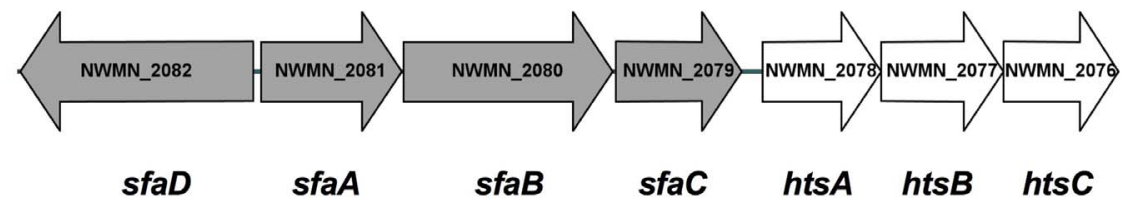

sfaB

sfac

htsA htsB hts C

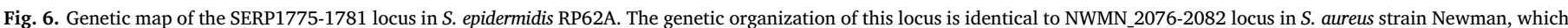

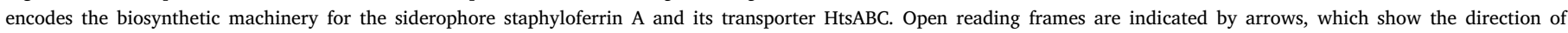
transcription. Putative Fur boxes were identified in the intergenic regions. 
the expression of genes in response to intracellular iron levels, exerting their action by binding with high affinity to a 19-bp inverted repeat sequence known as the Fur box (Baichoo and Helmann, 2002). In general, the presence of a Fur box consensus sequence overlapping or upstream a given gene is predictive that it is iron-regulated via Fur activity (Lee and Helmann, 2007). From our analysis, we were able to identify putative Fur box sequences up- or downstream every single gene/locus tested, suggesting that their expresion is regulated not only by iron levels but also in a Fur-dependent manner.

\subsection{S. epidermidis uses distinct mechanisms to acquire iron and maintain} iron homeostasis

To experimentally confirm the role of the aforementioned genes, biofilms of different strains were grown under iron-enriched $\left(\mathrm{Fe}^{+}\right)$or iron-deficient $\left(\mathrm{Fe}^{-}\right)$culture conditions $\left(\mathrm{TSB}_{\mathrm{G}}\right.$ supplemented with $1 \mathrm{mM}$ $\mathrm{FeCl}_{3}$ or $1 \mathrm{mM}$ Bip, respectively), and the transcription of those genes was evaluated through qPCR. Remarkably, transcription of genes putatively encoding components of a siderophore transporter (SERPO4000402, SERP1775-1776, and SERP0306) and siderophore biosynthesisrelated proteins (SERP1778-1779) were found to be up-regulated under $\mathrm{Fe}^{-}$conditions (Table 5-A/B). This suggests that $S$. epidermidis relies on a siderophore-mediated strategy to overcome iron limitation. Interestingly, SERP1775-1776 and SERP1778-1779 transcripts were also found to be slightly increased under $\mathrm{Fe}^{+}$conditions, while SERP0306 was clearly downregulated for this condition. Whether siderophore production also takes place when iron is readily available should be the aim of future research.

Transcription of SERP0949 and SERP0403 was also found to be significantly up-regulated under $\mathrm{Fe}^{-}$conditions (except in strain PT11006) (Table 5-B). The most likely hypothesis is that these putative siderophore-binding proteins may have affinity either for iron-siderophore or iron-Bip complexes. Further experimental confirmation should be achieved through characterization of these proteins for substrate specificity.

Lastly, SERP1951 transcript levels (Table 5-C) were significantly higher under $\mathrm{Fe}^{+}$. This supports the role of SERP1951 as part of an efflux pump which controls iron-associated toxicity. Under $\mathrm{Fe}^{-}$conditions, its transcription remained either unchanged or downregulated, indicating that cells were attempting to hold as much intracellular iron as possible. On the other hand, SERP1953 (hssR) was found to be equally expressed between the two conditions (Table 5-D). Besides, and in comparison with the control condition $\left(\mathrm{TSB}_{\mathrm{G}}\right.$ only), its expression did not suffer any change, except for strain PT12003. Taking into account its putative role as part of a two-component heme regulatory system, one would expect an altered expression in response to a disruption in iron availability, which would in turn activate/deactivate the expression of the efflux pump HrtAB. Adding to this, a putative Fur box was identified upstream its coding sequece, hence suggesting an iron-regulated transcription. Nevertheless, and although this study does not elucidate the role of HssR, it seems that unlike $S$. aureus the activation/ repression of HrtAB in S. epidermidis does not rely on the HssRS system.

Based on both bioinformatics analysis and transcriptomics data, a model portraying the different mechanisms that $S$. epidermidis employs to acquire iron and maintain its homeostasis is proposed in Fig. 7.

\section{Discussion}

It has been well established that virtually all microorganisms rely on iron to proliferate whereupon this dependence have been explored as a potential therapeutic target (Miethke and Marahiel, 2007). Regarding staphylococci, relevant research on this topic has been published. However, not only these studies have mostly been performed on planktonic growth, but also a strong focus on $S$. aureus is noticeable (Beasley et al., 2009; Brozyna et al., 2014; Cornelis and Dingemans, 2013; Dale et al., 2004). As a major cause of bloodstream infections (Widerström et al., 2012), S. epidermidis is thought to have efficient mechanisms to overcome severe iron restriction found in an environment like blood. This study sheds light into how disruptions in iron homeostasis severely impact $S$. epidermidis biofilm formation, especially when iron becomes a limiting nutrient. With regards to this, it is important to take into account that this bacterial species is primarily a major commensal inhabitant of the human skin, which is regarded as an iron-replete environment (Ledala et al., 2014). As a result, it is not surprising that biofilm formation is not hampered by a wide range of iron concentrations, even those off the physiologic levels (up to $0.10 \mathrm{mM}$ ). Nonetheless, and despite iron being indispensable for life, it is known that its excess leads to abnormal production of reactive oxygen species, which in turn leads to cellular damage (Oliveira et al., 2014). A scenario of iron excess was simulated by adding $1 \mathrm{mM} \mathrm{FeCl}_{3}$ to

Table 5

Effect of iron availability on the transcription of putative iron-related genes

\begin{tabular}{|c|c|c|c|c|c|c|c|c|c|c|c|}
\hline \multirow[t]{2}{*}{ Process } & \multirow[t]{2}{*}{ Gene } & \multirow[t]{2}{*}{ Putative function } & \multicolumn{3}{|l|}{ RP62A } & \multicolumn{3}{|l|}{ PT11006 } & \multicolumn{3}{|l|}{ PT12003 } \\
\hline & & & $\mathrm{Fe}^{+}$ & $\mathrm{Fe}^{-}$ & $\mathrm{P}$ value $\mathrm{e}^{\mathrm{a}}$ & $\mathrm{Fe}^{+}$ & $\mathrm{Fe}^{-}$ & $P$ value ${ }^{a}$ & $\mathrm{Fe}^{+}$ & $\mathrm{Fe}^{-}$ & P value ${ }^{a}$ \\
\hline \multirow[t]{2}{*}{ A) Siderophore biosynthesis } & SERP1778 & Amino-acid racemase & 1,856 & 2,509 & 0,5853 & 0,701 & 2,982 & 0,0838 & 2,268 & 3,259 & 0,4949 \\
\hline & SERP1779 & Siderophore synthetase & 2,283 & 2,866 & 0,6262 & 1,468 & 4,036 & 0,0526 & 1,793 & 3,252 & 0,3166 \\
\hline \multirow{8}{*}{$\begin{array}{l}\text { B) Siderophore uptake (ABC } \\
\text { transporter) }\end{array}$} & SERP1775 & Permease & 0,494 & 2,279 & 0,1398 & 1,355 & 2,649 & 0,3216 & 1,959 & 3,088 & 0,4372 \\
\hline & SERP1776 & Permease & 0,019 & 1,938 & 0,1131 & 1,114 & 3,569 & 0,0634 & 2,059 & 3,761 & 0,2434 \\
\hline & SERP0306 & ATP-binding protein & $-1,349$ & 2,928 & 0,0008 & $-2,252$ & 0,007 & 0,0867 & $-0,785$ & 3,795 & 0,0026 \\
\hline & SERPO4OO & Permease & $-0,306$ & 2,837 & 0,0110 & 0,052 & 1,604 & 0,4193 & 1,055 & 4,893 & 0,0105 \\
\hline & SERP0401 & Permease & $-0,290$ & 3,399 & 0,0032 & 1,425 & 2,117 & 0,5950 & 1,559 & 5,070 & 0,0186 \\
\hline & SERP0402 & ATP-binding protein & $-0,269$ & 2,699 & 0,0160 & 1,661 & 1,966 & 0,8148 & 1,660 & 4,924 & 0,0281 \\
\hline & SERP0403 & Siderophore-binding protein & $-0,435$ & 2,666 & 0,0121 & 1,699 & 1,800 & 0,9375 & 1,808 & 4,495 & 0,0685 \\
\hline & SERP0949 & Siderophore-binding protein & $-0,252$ & 4,091 & 0,0006 & 2,053 & $-1,172$ & 0,0160 & 0,881 & 4,612 & 0,0127 \\
\hline C) Heme-regulated transport & SERP1951 & ATP-binding protein & 1,471 & $-3,775$ & $<0,0001$ & 7,602 & $-0,480$ & $<0,0001$ & 4,698 & 0,279 & 0,0036 \\
\hline D) Heme sensing system & SERP1953 & $\begin{array}{l}\text { DNA-binding response } \\
\text { regulator }\end{array}$ & $-0,114$ & 0,414 & 0,6586 & 0,643 & 0,126 & 0,6905 & 1,686 & 1,980 & 0,8559 \\
\hline
\end{tabular}

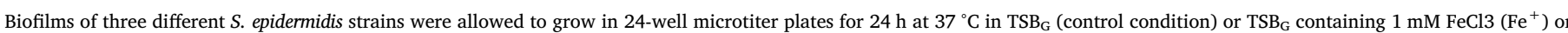

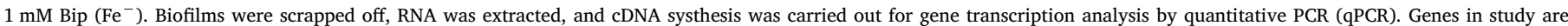

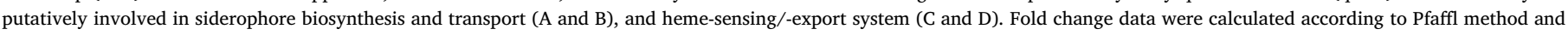

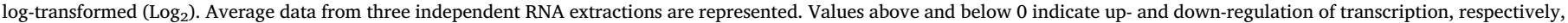
in comparison to the control condition $\left(\mathrm{TSB}_{\mathrm{G}}\right)$;

a Two-away ANOVA with multiple comparisons test was used to detect differences in transcription between $\mathrm{Fe}^{+}$and $\mathrm{Fe}^{-}$conditions. $p<0.05$ was considered statistically significant (significant differences depicted in bold). 
A)

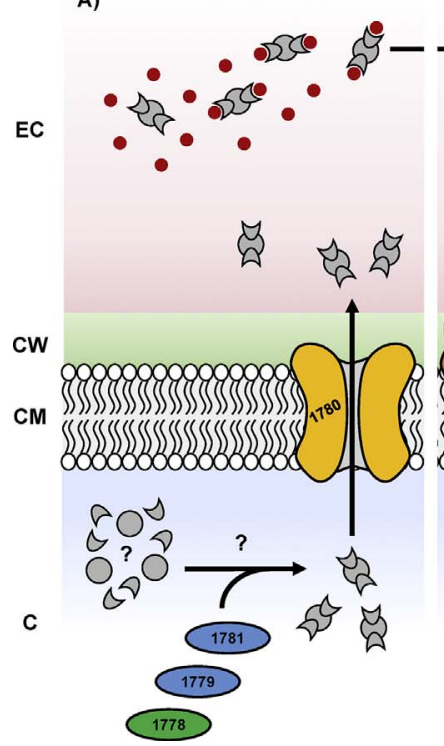

B)

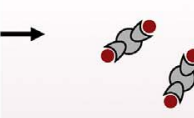

C) and D)

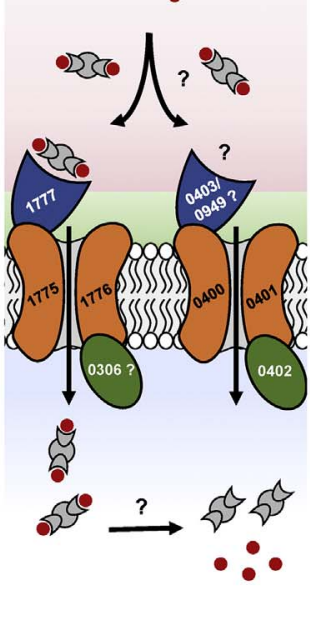

0

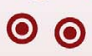

$\circ$ 0 ○ 0 8

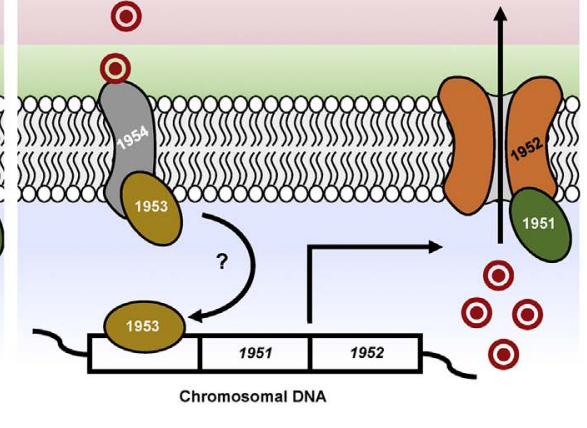

0 ○ ○

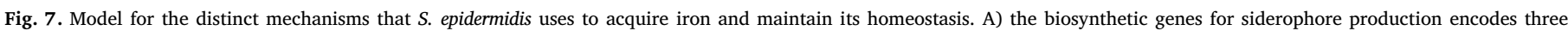

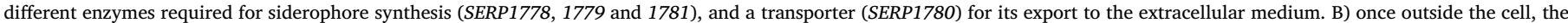

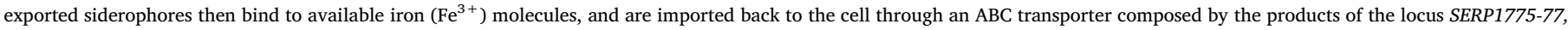

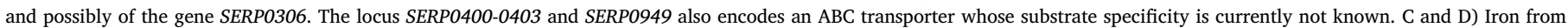

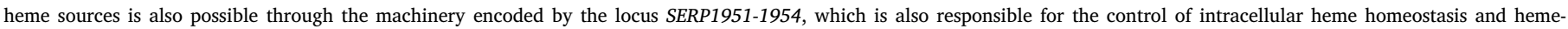
associated toxicity (for detailed information about this process in S. aureus please refer to Friedman et al., 2006 and Torres et al., 2007).

For information on transcriptional studies of processes A, B, C, and D please refer to Table 5.

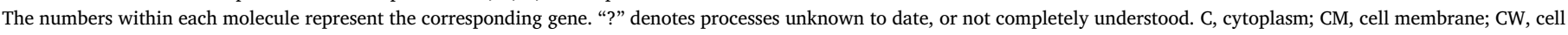
wall; EC, extracellular space; MFS, Multiple Facilitator Superfamily.

the culture medium routinely used, and a compromised biofilm formation was in fact detected for this condition. Surprisingly, such observation was not accompanied neither by an impaired planktonic growth rate, nor by a significant decrease in cell viability and cultivability. Taking into account such high concentration did negatively affect biofilm but not planktonic growth, we hypothesized that extreme iron concentrations somehow trigger cells to adopt a planktonic, freefloating lifestyle. Surprisingly, it was observed quite the opposite: the higher the iron concentration is, the lower the proportion of suspended cells in the whole cultivable population. This, in turn, suggested that cells were not being dispersed/detached from the biofilm. A temporal analysis of biofilm formation showed that the reduced biofilm formation initially observed is essentially the result of a reduced cell attachment and further accumulation, ruling out the hypothesis that cells are being detached from the biofilm. Impaired production of extracellular matrix might also contribute for this phenotype, even though not related with PIA/PNAG production. Studies on Pseudomonas aeruginosa, a microorganism for which iron-related research is more developed, have shown that elevated iron concentrations also have an inhibitory effect on biofilm formation (Musk et al., 2005), which seems to be related with decreased release of extracellular DNA (Yang et al., 2007).

On the contrary, iron-limiting conditions have proven to be severely deleterious for biofilm formation, which is partly explained by a reduced growth rate, but also by reduced cell viability and culturability, and consequent decreased PIA/PNAG production. Interestingly, studies carried out on $S$. aureus report contradictory outcomes. Similarly to what we have found, Lin and colleagues demonstrated that iron depletion has a detrimental effect on biofilm formation, which is mainly related with decreased cell adherence and PIA/PNAG production (Lin et al., 2012). However, Johnson et al. showed that biofilm formation was induced in low-iron growth conditions (Johnson et al., 2005). Of note, these studies used different strains and culture media, hence it is conceivable that the observed differences were the result of strain-tostrain variation, as found in other studies (França et al., 2013; Oliveira et al., 2015), or due to differences in the experiment design itself. To account for this kind of variation, three different strains were used across our entire experiments. Taken together, our data shows that a reduced biofilm formation under low-iron conditions is mainly attributable to changes in cells themselves. Interestingly, it seems clear that most $S$. epidermidis cells are induced to grow as a biofilm either by iron excess or deficiency, even though the latter condition caused a reduction in the total number of cells. It has long been hypothesized that cells growing under certain conditions, namely nutrient limitation or presence of toxic compounds, are induced to adopt a biofilm lifestyle (Donlan and Costerton, 2002), which is in accordance to what we have observed from our experiments.

Another aim of this study was to explore the molecular mechanisms that $S$. epidermidis employs to acquire iron and maintain its homeostasis, which remains unknown to date. Beasley et al., 2009 reported that the sfa-hts locus, known to encode proteins involved in siderophore biosynthesis and its import, is conserved in the coagulase-negative staphylococci for which genomic sequences are available.

Here, we provide both in silico and experimental evidence that such cluster of genes is iron-regulated, supporting the role of this locus in siderophore bionsynthesis/transport, as well as opening the door for further in-depth characterization of siderophore production in $S$. epidermidis. Besides, other genetic loci putatively encoding siderophore transporters were identified, the transcription of which has also been shown to be triggered by iron-limiting conditions. Therefore, our data strongly suggest that $S$. epidermidis relies on siderophore production as a means to acquire iron. However, contrary to $S$. aureus, S. epidermidis seems to have the necessary machinery for the production of one single siderophore, yet it has different transporters for its internalization. Whether such transporters are specific or may function as alternative uptake systems for siderophores produced by other bacterial species should be the target of future research.

Also, S. epidermidis is equiped with an homolog of $S$. aureus HrtA. HrtA is part of an efflux pump system in $S$. aureus that allows cells to cope with heme-associated toxicity (Torres et al., 2007). However, the 
mechanism behind its activation/repression seems to be different in both species. When $S$. epidermidis cells were cultured under iron excess, it was observed a conflicting result. According to our transcriptional studies, cells exhibited increased $h r t A$ transcription (indicative of excess iron being exported out of the cell), and simultaneously increased transcription of siderophore biosynthetic genes (indicative of active siderophore production). Even though our results suggest that ironsiderophore complexes were not being internalized under this condition, this worths further investigation.

Collectively, the results reported in this study support the hypothesis that targeting iron metabolism may be an attractive strategy to prevent biofilm development by this species. This may be accomplished either by reducing the iron availability in the surrounding medium, or by interfering with its acquisition. Meanwhile, a better comprehension about the molecular mechanisms behind this process must be accomplished in a near future.

\section{Conflict of interests}

The authors declare that they have no conflict of interest.

\section{Acknowledgements}

This study was supported by the Portuguese Foundation for Science and Technology (FCT) under the scope of the strategic funding of UID/ BIO/04469/2013 unit and COMPETE 2020 (POCI-01-0145-FEDER006684) and the project RECI/BBB-EBI/0179/2012 (FCOMP-01-0124FEDER-027462). FO and AF acknowledges the Portuguese Foundation for Science and Tecnology for the financial support through the individual grants SFRH/BD/101399/2014 and SFRH/BPD/99961/2014. $\mathrm{NC}$ is an Investigador FCT.

\section{Appendix A. Supplementary data}

Supplementary data associated with this article can be found, in the online version, at http://dx.doi.org/10.1016/j.ijmm.2017.08.009.

\section{References}

Altschul, S.F., Gish, W., Miller, W., Myers, E.W., Lipman, D.J., 1990. Basic local alignment search tool. J. Mol. Biol. 215, 403-410. http://dx.doi.org/10.1016/S0022-2836(05) 80360-2.

Baichoo, N., Helmann, J.D., 2002. Recognition of DNA by Fur: a reinterpretation of the Fur box consensus sequence. J. Bacteriol. 184, 5826-5832. http://dx.doi.org/10. 1128/JB.184.21.5826-5832.2002.

Banin, E., Vasil, M.L., Greenberg, E.P., 2005. Iron and Pseudomonas aeruginosa biofilm formation. Proc. Natl. Acad. Sci. U. S. A. 102, 11076-11081. http://dx.doi.org/10. 1073/pnas.0504266102.

Beasley, F.C., Heinrichs, D.E., 2010. Siderophore-mediated iron acquisition in the staphylococci. J. Inorg. Biochem. 104, 282-288. http://dx.doi.org/10.1016/j.jinorgbio. 2009.09.011.

Beasley, F.C., Vinés, E.D., Grigg, J.C., Zheng, Q., Liu, S., Lajoie, G.A., Murphy, M.E.P., Heinrichs, D.E., 2009. Characterization of staphyloferrin A biosynthetic and transport mutants in Staphylococcus aureus. Mol. Microbiol. 72, 947-963. http://dx.doi.org/10. 1111/j.1365-2958.2009.06698.x.

Beasley, F.C., Marolda, C.L., Cheung, J., Buac, S., Heinrichs, D.E., 2011. Staphylococcus aureus transporters Hts, Sir, and Sst capture iron liberated from human transferrin by staphyloferrin A, staphyloferrin B, and catecholamine stress hormones, respectively, and contribute to virulence. Infect. Immun. 79, 2345-2355. http://dx.doi.org/10. 1128/iai.00117-11.

Brozyna, J.R., Sheldon, J.R., Heinrichs, D.E., 2014. Growth promotion of the opportunistic human pathogen, Staphylococcus lugdunensis, by heme, hemoglobin, and coculture with Staphylococcus aureus. Microbiologyopen 3, 182-195. http://dx.doi. org/10.1002/mbo3.162.

Cerca, N., Martins, S., Sillankorva, S., Jefferson, K.K., Pier, G.B., Oliveira, R., Azeredo, J., 2005. Effects of growth in the presence of subinhibitory concentrations of dicloxacillin on Staphylococcus epidermidis and Staphylococcus haemolyticus biofilms. Appl. Environ. Microbiol. 71, 8677-8682. http://dx.doi.org/10.1128/AEM.71.12.86778682.2005 .

Cerca, N., Jefferson, K.K., Oliveira, R., Pier, G.B., Azeredo, J., 2006. Comparative antibody-mediated phagocytosis of Staphylococcus epidermidis cells grown in a biofilm or in the planktonic state. Infect. Immun. 74, 4849-4855. http://dx.doi.org/10.1128/ IAI.00230-06.

Cerca, F., Trigo, G., Correia, A., Cerca, N., Azeredo, J., Vilanova, M., 2011. SYBR green as a fluorescent probe to evaluate the biofilm physiological state of Staphylococcus epidermidis, using flow cytometry. Can. J. Microbiol. 57, 850-856. http://dx.doi.org/10 1139/w11-078.

Cheung, G.Y.C., Otto, M., 2010. Understanding the significance of Staphylococcus epidermidis bacteremia in babies and children. Curr. Opin. Infect. Dis. 23, 208-216. http://dx.doi.org/10.1097/QCO.0b013e328337fecb.

Cornelis, P., Dingemans, J., 2013. Pseudomonas aeruginosa adapts its iron uptake strategies in function of the type of infections. Front. Cell. Infect. Microbiol. 3, 75. http:// dx.doi.org/10.3389/fcimb.2013.00075.

Crosa, J.H., Walsh, C.T., 2002. Genetics and assembly line enzymology of siderophore biosynthesis in bacteria. Microbiol. Mol. Biol. Rev. 66, 223-249. http://dx.doi.org/ 10.1128/MMBR.66.2.223-249.2002.

Dale, S.E., Sebulsky, M.T., Heinrichs, D.E., 2004. Involvement of SirABC in iron-siderophore import in Staphylococcus aureus. J. Bacteriol. 186, 8356-8362. http://dx.doi. org/10.1128/JB.186.24.8356-8362.2004.

De Lorenzo, V., Wee, S., Herrero, M., Neilands, J.B., 1987. Operator sequences of the aerobactin operon of plasmid ColV-K30 binding the ferric uptake regulation (fur) repressor. J. Bacteriol. 169, 2624-2630. http://dx.doi.org/10.1128/jb.169.6.2624 2630.1987.

Donlan, R.M., Costerton, J.W., 2002. Biofilms: survival mechanisms of clinically relevant microorganisms. Clin. Microbiol. Rev. 15, 167-193. http://dx.doi.org/10.1128/ CMR.15.2.167-193.2002.

Donlan, R.M., 2001. Biofilms and device-associated infections. Emerg. Infect. Dis. 7, 277-281. http://dx.doi.org/10.3201/eid0702.700277.

França, A., Freitas, A.I., Henriques, A.F., Cerca, N., 2012. Optimizing a qPCR gene expression quantification assay for $S$. epidermidis biofilms: a comparison between commercial kits and a customized protocol. PLoS One 7, e37480. http://dx.doi.org/ 10.1371/journal.pone.0037480.

França, A., Vilanova, M., Cerca, N., Pier, G.B., 2013. Monoclonal antibody raised against PNAG has variable effects on static $S$. epidermidis biofilm accumulation in vitro. Int. J. Biol. Sci. 9, 518-520. http://dx.doi.org/10.7150/ijbs.6102.

França, A., Carvalhais, V., Maira-Litrán, T., Vilanova, M., Cerca, N., Pier, G., 2014. Alterations in the Staphylococcus epidermidis biofilm transcriptome following interaction with whole human blood. Pathog. Dis. 70, 444-448. http://dx.doi.org/10. 1111/2049-632X.12130.

França, A., Carvalhais, V., Vilanova, M., Pier, G.B., Cerca, N., 2016. Characterization of an in vitro fed-batch model to obtain cells released from $S$. epidermidis biofilms. AMB Express 6, 23. http://dx.doi.org/10.1186/s13568-016-0197-9.

Freitas, A.I., Vasconcelos, C., Vilanova, M., Cerca, N., 2014. Optimization of an automatic counting system for the quantification of Staphylococcus epidermidis cells in biofilms. J. Basic Microbiol. 54, 750-757. http://dx.doi.org/10.1002/jobm.201200603.

Friedman, D.B., Stauff, D.L., Pishchany, G., Whitwell, C.W., Torres, V.J., Skaar, E.P., 2006. Staphylococcus aureus redirects central metabolism to increase iron availability. PLoS Pathog. 2, 0777-0789. http://dx.doi.org/10.1371/journal.ppat.0020087.

Grant, C.E., Bailey, T.L., Noble, W.S., 2011. FIMO: Scanning for occurrences of a given motif. Bioinformatics 27, 1017-1018. http://dx.doi.org/10.1093/bioinformatics/ btr064.

Hammer, N.D., Skaar, E.P., 2011. Molecular mechanisms of Staphylococcus aureus iron acquisition. Annu. Rev. Microbiol. 65, 129-147. http://dx.doi.org/10.1146/annurevmicro-090110-102851.

Hayrapetyan, H., Siezen, R., Abee, T., Groot, M.N., 2016. Comparative genomics of irontransporting systems in Bacillus cereus strains and impact of iron sources on growth and biofilm formation. Front. Microbiol. 7, 1-13. http://dx.doi.org/10.3389/fmicb. 2016.00842

Jabbouri, S., Sadovskaya, I., 2010. Characteristics of the biofilm matrix and its role as a possible target for the detection and eradication of Staphylococcus epidermidis associated with medical implant infections. FEMS Immunol. Med. Microbiol. 59, 280-291. http://dx.doi.org/10.1111/j.1574-695X.2010.00695.x.

Johnson, M., Cockayne, A., Williams, P.H., Morrissey, J.A., 2005. Iron-responsive regulation of biofilm formation in Staphylococcus aureus involves Fur-dependent and Furindependent mechanisms. J. Bacteriol. 187, 8211-8215. http://dx.doi.org/10.1128/ JB.187.23.8211-8215.2005.

Knobloch, J.K.-M., Horstkotte, M.A., Rohde, H., Kaulfers, P.-M., Mack, D., 2002. Alcoholic ingredients in skin disinfectants increase biofilm expression of Staphylococcus epidermidis. J. Antimicrob. Chemother. 49, 683-687. http://dx.doi.org/10.1093/jac/49. 4.683.

Ledala, N., Zhang, B., Seravalli, J., Powers, R., Somerville, G.A., 2014. Influence of iron and aeration on Staphylococcus aureus growth, metabolism, and transcription. J. Bacteriol. 196, 2178-2189. http://dx.doi.org/10.1128/JB.01475-14.

Lee, J.-W., Helmann, J.D., 2007. Functional specialization within the Fur family of metalloregulators. Biometals 20, 485-499. http://dx.doi.org/10.1007/s10534-0069070-7.

Lin, M.H., Shu, J.C., Huang, H.Y., Cheng, Y.C., 2012. Involvement of iron in biofilm formation by Staphylococcus aureus. PLoS One 7, e34388. http://dx.doi.org/10.1371/ journal.pone.0034388.

Lindsay, J.A., Riley, T.V., Mee, B.J., 1994. Production of siderophore by coagulase-negative staphylococci and its relation to virulence. Eur. J. Clin. Microbiol. Infect. Dis. 13, 1063-1066. http://dx.doi.org/10.1007/BF02111829.

Mack, D., Davies, A.P., Harris, L.G., Rohde, H., Horstkotte, M.A., Knobloch, J.K.M., 2007. Microbial interactions in Staphylococcus epidermidis biofilms. Anal. Bioanal. Chem. 387, 399-408. http://dx.doi.org/10.1007/s00216-006-0745-2.

Miethke, M., Marahiel, M.A., 2007. Siderophore-based iron acquisition and pathogen control. Microbiol. Mol. Biol. Rev. 71, 413-451. http://dx.doi.org/10.1128/MMBR. 00012-07.

Mladěnka, P., Macáková, K., Zatloukalová, L., Řeháková, Z., Singh, B.K., Prasad, A.K., Parmar, V.S., Jahodář, L., Hrdina, R., Saso, L., 2010. In vitro interactions of coumarins 
with iron. Biochimie 92, 1108-1114. http://dx.doi.org/10.1016/j.biochi.2010.03. 025 .

Morrissey, J. a., Cockayne, A., Hill, P.J., Williams, P., 2000. Molecular cloning and analysis of a putative siderophore $\mathrm{ABC}$ transporter from Staphylococcus aureus. Infect. Immun. 68, 6281-6288.

Musk, D.J., Banko, D.A., Hergenrother, P.J., 2005. Iron salts perturb biofilm formation and disrupt existing biofilms of Pseudomonas aeruginosa. Chem. Biol. 12, 789-796. http://dx.doi.org/10.1016/j.chembiol.2005.05.007.

Oliveira, F., Rocha, S., Fernandes, R., 2014. Iron metabolism: from health to disease. J. Clin. Lab. Anal. 28, 210-218. http://dx.doi.org/10.1002/jcla.21668.

Oliveira, F., Lima, C.A., Bráss, S., França, A., Cerca, N., 2015. Evidence for inter- and intraspecies biofilm formation variability among a small group of coagulase-negative staphylococci. FEMS Microbiol. Lett. 362. http://dx.doi.org/10.1093/femsle/fnv175.

Otto, M., 2009. Staphylococcus epidermidis - the accidental pathogen. Nat. Rev. Microbiol. 7, 555-567. http://dx.doi.org/10.1038/nrmicro2182.

Pfaffl, M.W., Pfaffl, M.W., 2001. A new mathematical model for relative quantification in real-time RT-PCR. Nucleic Acids Res. 29, e45. http://dx.doi.org/10.1093/nar/29.9. e45.

Reid, D.W., O'May, C., Kirov, S.M., Roddam, L., Lamont, I.L., Sanderson, K., 2009. Iron chelation directed against biofilms as an adjunct to conventional antibiotics. AJP Lung Cell. Mol. Physiol. 296, L857-L858. http://dx.doi.org/10.1152/ajplung.00058. 2009.

Rohde, H., Mack, D., Christner, M., Burdelski, C., Franke, G., Knobloch, J.K.-M., 2006. Pathogenesis of staphylococcal device-related infections: from basic science to new diagnostic, therapeutic and prophylactic approaches. Rev. Med. Microbiol. 17, 45-54. http://dx.doi.org/10.1097/01. revmedmi.0000244134.43170.83.

Rohde, H., Burandt, E.C., Siemssen, N., Frommelt, L., Burdelski, C., Wurster, S., Scherpe, S., Davies, A.P., Harris, L.G., Horstkotte, M.A., Knobloch, J.K.M., Ragunath, C., Kaplan, J.B., Mack, D., 2007. Polysaccharide intercellular adhesin or protein factors in biofilm accumulation of Staphylococcus epidermidis and Staphylococcus aureus isolated from prosthetic hip and knee joint infections. Biomaterials 28, 1711-1720. http://dx.doi.org/10.1016/j.biomaterials.2006.11.046.

Schindelin, J., Arganda-Carreras, I., Frise, E., Kaynig, V., Longair, M., Pietzsch, T., Preibisch, S., Rueden, C., Saalfeld, S., Schmid, B., Tinevez, J.-Y., White, D.J., Hartenstein, V., Eliceiri, K., Tomancak, P., Cardona, A., 2012. Fiji: an open-source platform for biological-image analysis. Nat. Methods 9, 676-682. http://dx.doi.org/ 10.1038/nmeth.2019.
Skaar, E.P., 2010. The battle for iron between bacterial pathogens and their vertebrate hosts. PLoS Pathog. 6, e1000949. http://dx.doi.org/10.1371/journal.ppat.1000949.

Speziali, C.D., Dale, S.E., Henderson, J.A., Vinés, E.D., Heinrichs, D.E., 2006. Requirement of Staphylococcus aureus ATP-binding cassette-ATPase FhuC for iron-restricted growth and evidence that it functions with more than one iron transporter. J. Bacteriol. 188, 2048-2055. http://dx.doi.org/10.1128/JB.188.6.2048-2055.2006.

Stepanovic, S., Vukovic, D., Hola, V., Di Bonaventura, G., Djukic, S., Cirkovi, I., Ruzicka, F., 2007. Quantification of biofilm in microtiter plates: overview of testing conditions and practical recommendations for assessment of biofilm production by staphylococci. APMIS 115, 891-899. http://dx.doi.org/10.1111/j.1600-0463.2007. apm_ 630.x.

Torres, V.J., Stauff, D.L., Pishchany, G., Bezbradica, J.S., Gordy, L.E., Iturregui, J., Anderson, K.L.L., Dunman, P.M., Joyce, S., Skaar, E.P., 2007. A Staphylococcus aureus regulatory system that responds to host heme and modulates virulence. Cell Host Microbe 1, 109-119. http://dx.doi.org/10.1016/j.chom.2007.03.001.

Untergasser, A., Cutcutache, I., Koressaar, T., Ye, J., Faircloth, B.C., Remm, M., Rozen, S.G., 2012. Primer3-new capabilities and interfaces. Nucleic Acids Res. 40. http://dx. doi.org/10.1093/nar/gks596.

Weinberg, E.D., 2004. Suppression of bacterial biofilm formation by iron limitation. Med. Hypotheses 63, 863-865. http://dx.doi.org/10.1016/j.mehy.2004.04.010.

Widerström, M., Wiström, J., Sjöstedt, A., Monsen, T., 2012. Coagulase-negative staphylococci: update on the molecular epidemiology and clinical presentation, with a focus on Staphylococcus epidermidis and Staphylococcus saprophyticus. Eur. J. Clin. Microbiol. Infect. Dis. 31, 7-20. http://dx.doi.org/10.1007/s10096-011-1270-6.

Worwood, M., 2014. Disorders of iron metabolism. In: Williams, D.L., Marks, V. (Eds.), Scientific Foundations of Biochemistry in Clinical Practice. Butterworth-Heinemann, Oxford, UK, pp. 446-452.

Yang, L., Barken, K.B., Skindersoe, M.E., Christensen, A.B., Givskov, M., Tolker-Nielsen, T., 2007. Effects of iron on DNA release and biofilm development by Pseudomonas aeruginosa. Microbiology 153, 1318-1328. http://dx.doi.org/10.1099/mic.0.2006/ 004911-0.

Ye, J., Coulouris, G., Zaretskaya, I., Cutcutache, I., Rozen, S., Madden, T.L., 2012. PrimerBLAST: A tool to design target-specific primers for polymerase chain reaction. BMC Bioinf. 13, 134. http://dx.doi.org/10.1186/1471-2105-13-134.

Zuker, M., 2003. Mfold web server for nucleic acid folding and hybridization prediction. Nucleic Acids Res. 31, 3406-3415. http://dx.doi.org/10.1093/nar/gkg595. 